\title{
Rapport préliminaire sur les travaux de la mission archéologique de Zeyve höyük-Porsuk 2015
}

Dominique Beyer, Isabelle Chalier et Françoise Kirner

\section{(2) OpenEdition \\ 1 Journals}

Édition électronique

URL : http://journals.openedition.org/anatoliaantiqua/386

DOI : 10.4000/anatoliaantiqua.386

Éditeur

IFEA

Édition imprimée

Date de publication : 1 mai 2016

Pagination : 253-280

ISBN : 9782362450648

ISSN : 1018-1946

Référence électronique

Dominique Beyer, Isabelle Chalier et Françoise Kirner, « Rapport préliminaire sur les travaux de la

mission archéologique de Zeyve höyük-Porsuk 2015 », Anatolia Antiqua [En ligne], XXIV | 2016, mis en ligne le 11 décembre 2018, consulté le 16 février 2021. URL : http://journals.openedition.org/

anatoliaantiqua/386 ; DOI : https://doi.org/10.4000/anatoliaantiqua.386 


\section{ANATOLIA ANTIQUA ESKI ANADOLU}

\section{XXIV}

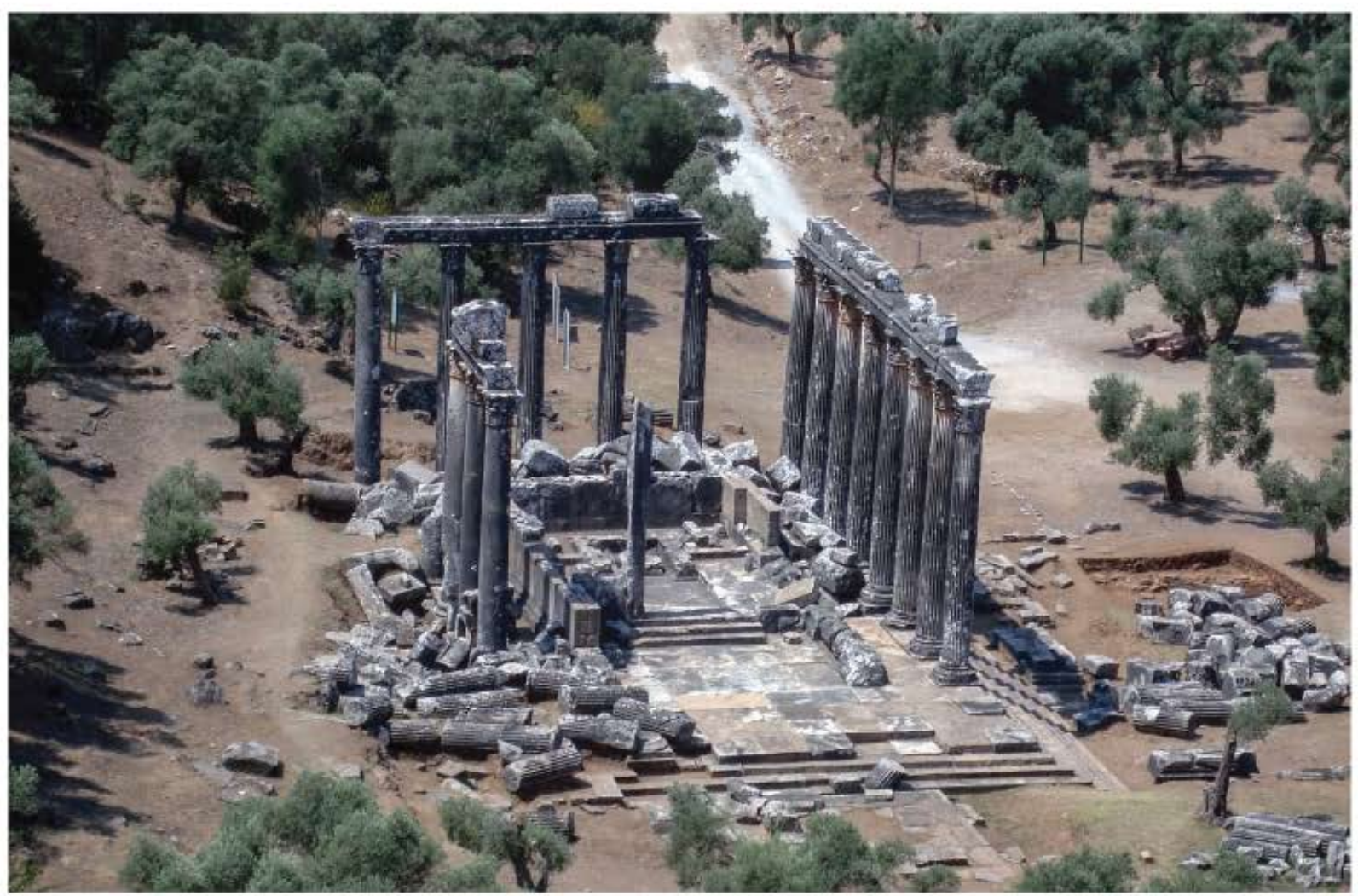

INSTITUT FRANÇAIS D'ETUDES ANATOLIENNES GEORGES-DUMEZIL

CNRS USR 3131

DE BOCCARD 


\section{TABLE DES MATIERES}

Ergul KODAS,

Le surmodelage du crâne au Néolithique au Proche-Orient : techniques de surmodelage et

expérimentations

Isabella CANEVA et Eric JEAN,

Mersin-Yumuktepe : une mise au point sur les derniers travaux

Turan EFE et Bérengère PERELLO,

Second Millenium site distribution and pottery of Inland Northwestern Anatolia

Antoine PEREZ,

Amida 6 : Antiochos IV, le "Hanigalbat" et la Sophène

Ergün LAFLI et Hadrien BRU,

Inscriptions et monuments funéraires gréco-romains d'Anatolie occidentale

Oğuz TEKİN et Aliye EROL-ÖZDİZBAY,

Coins from Allianoi excavations: Campaign of 2001

Nuran ŞAHIN,

Etude iconographique des monnaies autonomes frappées par Colophon-sur-Mer :

nouveaux acquis

Vera SAUER,

Konventionelle Individualität. Zur Münzprägung nordanatolischer Städte in der römischen

Kaiserzeit

Oğuz TEKIN,

Balance weights in the collection of the Anatolian Civilizations Museum in Ankara

\section{CHRONIQUES DES TRAVAUX ARCHEOLOGIQUES EN TURQUIE 2015}

Çiğdem MANER,

Preliminary report on the third season of the Konya-Ereğli Survey (KEYAR) 2015

Dominique BEYER, Isabelle CHALIER et Françoise KIRNER,

Rapport préliminaire sur les travaux de la mission archéologique de Zeyve Höyük-Porsuk 2015 ...

Sami PATACI et Ergün LAFLI,

Field surveys in Ardahan in 2015

Jean-Charles MORETTI avec la collaboration de Nicolas BRESCH, Isabel BONORA,

Jean-Jacques MALMARY et Olivier RISS,

Claros, le temple d'Apollon : travaux réalisés en 2015

Serdar Hakan ÖZTANER,

La basilique civile de Nysa du Méandre

Abuzer KIZIL, Koray KONUK, Patrice BRUN, Laurent CAPDETREY, Raymond DESCAT,

Pierre FROHLICH, Didier LAROCHE, Enora LE QUERE, Francis PROST, Baptiste VERGNAUD,

Eurômos : rapport préliminaire sur les travaux réalisés en 2015

O. HENRY et E. ANDERSON, Chr. BOST, Ö. ÇAKMAKLI, F. CEDERLING, A. COMMITO,

M. CORMIER-HUGUET, A. COUTELAS, A. DOLEA, D. ERGENÇ, A. FRECCERO,

A. FREJMAN, P. LEBOUTEILLER, F. LESGUER, D. LÖWENBORG, V. LUNGU,

Fr. MARCHAND-BEAULIEU, A. SITZ, P. DE STAEBLER, B. VERGNAUD, 


\section{Dominique BEYER*, Isabelle CHALIER* et Françoise KIRNER*}

\section{RAPPORT PRELIMINAIRE SUR LES TRAVAUX DE LA MISSION ARCHEOLOGIQUE DE ZEYVE HÖYÜK-PORSUK 2015}

Les travaux de la campagne de Porsuk 2105 ont eu lieu entre le 19 juillet et le 3 septembre. Les opérations sur le terrain ont été plus courtes que prévu en raison de la défection tardive du Dr. Can Karavul et de son équipe de géophysiciens de l'université turque de Sakarya qui devaient assurer l'essentiel du relevé géophysique durant le mois de juillet, avant le déroulement des fouilles. Il n'a pas été possible de les remplacer en raison du calendrier. L'opération de ce relevé géophysique du site, prévue depuis plusieurs années, mais réalisée partiellement seulement en $2014^{1}$, est donc une nouvelle fois retardée.

Il convient de souligner ici la souplesse et la compréhension dont a fait preuve à notre égard la Direction générale des Antiquités et Musées d'Ankara, en autorisant les travaux de la mission, malgré nos modestes effectifs et notre maigre budget, malgré le fait qu'un nouveau dépôt n'ait pas encore pu être aménagé, avec la nomination d'Aksel Tibet (secrétaire aux publications de l'IFEA) comme directeur adjoint turc, à titre provisoire. Cette année est considérée comme transitoire, dans la mesure où l'actuel directeur, en retraite depuis septembre 2014, et en fin de programme quadriennal, a souhaité être déchargé de ses responsabilités de directeur et pouvoir se consacrer en priorité aux travaux de publication $^{2}$ Les autorités archéologiques d'Ankara souhaitent visiblement que la mission puisse redémarrer avec une direction plus jeune, dynamique, et avec une équipe étoffée. La candidature de Claire Barat, maître de conférences à l'Université de Valenciennes, associée à Jean-François Pichonneau, Ingénieur de la DRAC de Bordeaux, est à cet égard la bienvenue. L'un et l'autre ont pu passer quelques jours en notre compagnie sur le terrain, se familiariser ainsi avec le site, ses possibilités et ses contraintes, et engager quelques démarches, entre autres dans la perspective d'un nouveau dépôt archéologique pour la mission, qui pourrait bénéficier du prêt d'un bâtiment appartenant au ministère de la Santé dans le village proche de Darboğaz.

Dans tous ces contacts et négociations préalables avec les diverses autorités, qui ont eu lieu en partie lors du Congrès archéologique annuel de la fin du mois de mai 2015 à Erzurum, il convient de souligner l'aide particulièrement efficace et dévouée de Martin Godon, responsable du Pôle Archéologie de l'IFEA, dont l'engagement à nos côtés est total.

Sur le terrain, les activités de fouille ont concerné, comme la plupart des années précédentes, le chantier II et le chantier IV ${ }^{3}$.

*) UMR 7044 ARCHIMEDE, Strasbourg.

1) Cf. Beyer, Karavul, Laroche-Traunecker et Tibet $2015: 283-286$.

2) En ce qui concerne la publication des travaux des missions Pelon et Beyer, consacrée aux chantiers du Bronze et du Fer Moyen, le travail est en cours, en collaboration étroite avec Françoise Laroche-Traunecker et Aksel Tibet.

3) Comme les années précédentes, nous devons à la compréhension de la commission des recherches à l'étranger du ministère des Affaires étrangères et européennes d'avoir pu fonctionner, même avec un budget toujours trop limité. L'UMR 7044 ARCHIMEDE a pu assurer la prise en charge de quelques voyages. Le directeur de l'IFEA a une nouvelle fois mis gracieusement à notre disposition l'indispensable véhicule Ford Transit sans lequel rien n'aurait pu être possible. Qu'il soit chaleureusement remercié pour son soutien.

La Direction générale des Antiquités et Musées d'Ankara avait dépêché auprès de la mission à titre de temsilci Hakan Erdoğan, membre du personnel du musée de Niğde. Nous devons le remercier pour toute son aide et sa compréhension. L'accueil au musée de Niğde, comme à l'accoutumée, a été chaleureux.

L'équipe habituelle a été cette année passablement réduite, puisque le projet initial devait porter, en priorité, sur le relevé géophysique. Si Aksel Tibet a pu passer une semaine sur le terrain, Françoise Laroche-Traunecker n'a pu rejoindre la mission en raison de problèmes de santé. La totalité des relevés d'architecture a été alors prise en charge par Alexis Beyer qui n'a pas ménagé sa peine et qui a réalisé en outre avec talent de nombreux dessins de matériel. Avec son efficacité coutumière, Ayşe Özkan s'est consacrée au dessin céramique pendant trois semaines durant le mois d'août. La mission a également bénéficié, pendant trois semaines de même, de l'aide d'une jeune archéologue-stagiaire franco-turque, Anna Signoret, dont les capacités linguistiques, entre autres, ont été fort utiles. 


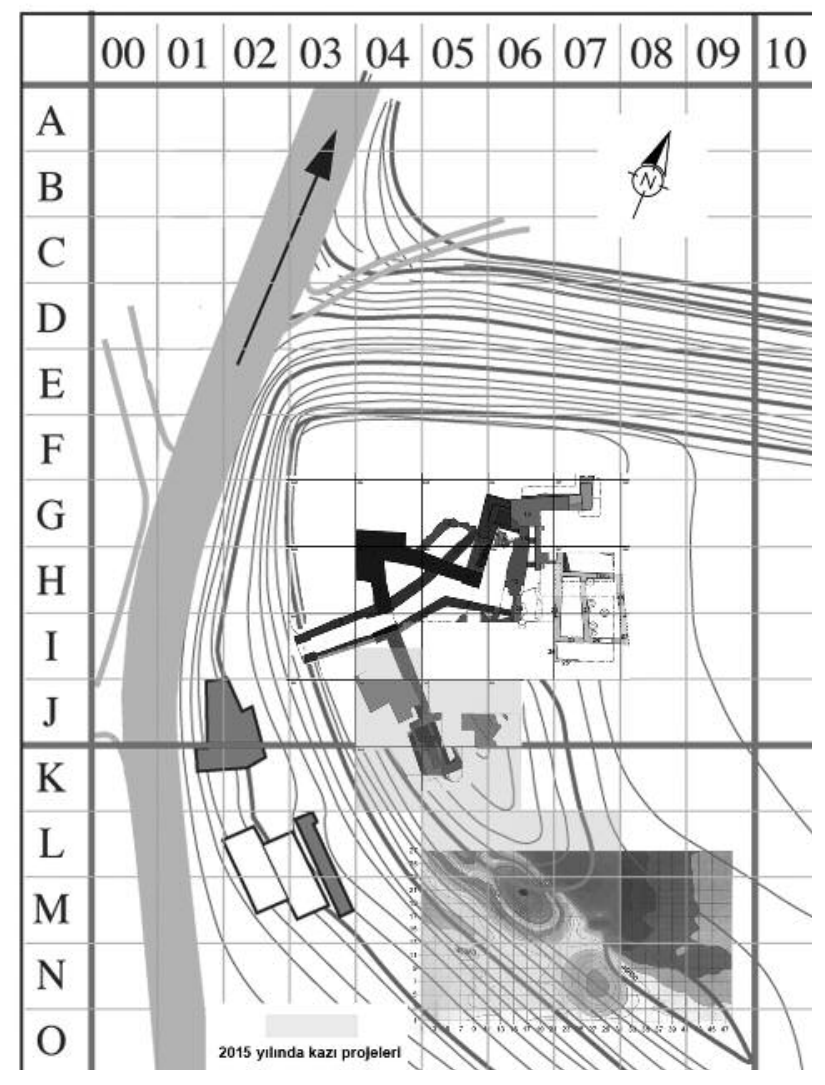

Fig. 1 : Plan du chantier II avec l'emplacement du secteur de fouille M06-07.

\section{LE CHANTIER II SUD (D. Beyer)}

Les travaux des géophysiciens en juillet 2014 avaient révélé, entre autres éléments, sur la pente sud de la butte occidentale du site (Fig. 1), en MN/06-07, la présence de deux masses architecturales importantes, avec briques brûlées, qui devaient correspondre, en raison de leur emplacement et de l'intervalle qui les sépare, à deux tours de défense de la fortification du second millénaire encadrant une porte de l'ancienne cité, identifiable avec la Tunna/Dunna des textes hittites ou assyriens. De plus, toujours selon les relevés géomagnétiques et de résistivité électrique opérés par les chercheurs de Sakarya, une "masse métallique" particulièrement importante était à rechercher en profondeur, à l'emplacement de la présumée tour nord-ouest, en M06.

C'est la raison pour laquelle ce carré M06 a été partiellement ouvert, sur une surface de 7,50 x 7,50 $\mathrm{m}$, avec par la suite une extension en M07. La pente assez forte dans ce secteur permettait d'espérer at- teindre rapidement les niveaux concernés, avec briques brûlées caractéristiques. Ce fut le cas en effet, mais il a fallu affronter néanmoins au préalable l'important éboulis de pierres du rempart de l'Age du Fer.

\section{Le niveau Porsuk III (Fer Moyen)}

Très rapidement sous la surface sont en effet apparues les pierres, en très grande majorité de gypse, appartenant aux restes de la fortification du niveau Porsuk III, bien connue par les travaux opérés il y a quelques années plus au Nord, en J-K/04-05, et qu'une analyse $\mathrm{C}_{14}$ sur des restes de chaînage de bois avaient permis de dater du Fer Moyen, vers 750 av. J.-C. Cette année, un tesson peint du Fer Moyen, parmi le rare matériel retrouvé, devrait pouvoir confirmer en gros cette datation. L'orientation générale de l'éboulis de pierres 03860 (Fig. 2a-b), Nord-Ouest/Sud-Est, est conforme à l'orientation générale du rempart, mais la fouille n'a pas pu déterminer l'épaisseur du mur ni en fournir un tracé précis. Seule la face sud-ouest de la muraille, la face externe, a pu être partiellement repérée, avec les vestiges, assez bien conservés, de pièces de bois non brûlées du chaînage, boutisses essentiellement, à intervalles réguliers, mais aussi boutisses associées à des longrines (Fig. 3), aux endroits où le mur de pierres a dû s'ancrer très profondément, en aval, à l'emplacement du vide correspondant au passage de la porte des niveaux antérieurs. En profondeur, les bâtisseurs de ce mur du Fer ont également opté pour l'utilisation fréquente de blocs de pierre plus conséquents, en grès, atteignant jusqu'à $60 \mathrm{~cm}$ en tous sens. Mais l'ensemble a été retrouvé passablement disloqué, en raison de la pente, des techniques de construction un peu rudimentaires et de la dégradation des pièces de renfort de bois.

La découverte, parmi les pierres du mur (Fig. 4), d'un squelette d'enfant (env. 5-6 ans) avait un temps été interprétée comme un possible dépôt de fondation pour ce rempart du Fer, car aucun indice de fosse n'avait pu être décelé, et aucune offrande funéraire retrouvée. La pratique de ce type de dépôt de fondation est attestée à Porsuk, dans la dénommée "poterne hittite", sous les murs, mais à vrai dire ceux du Bronze et non du Fer. La découverte par la suite, à proximité, et dans le même contexte des pierres de la muraille du Fer, de deux nouveaux squelettes, l'un d'un adulte de sexe féminin ${ }^{4}$, l'autre d'un adulte également, mais partiellement dégagé

4) Les deux premiers squelettes ont pu être examinés, même rapidement, et dans les conditions du chantier, par un anthropologue de l'équipe turque de la mission de Tepecik-Çiftlik, Ali Metin Büyükkarakaya, que nous remercions chaleureusement. 


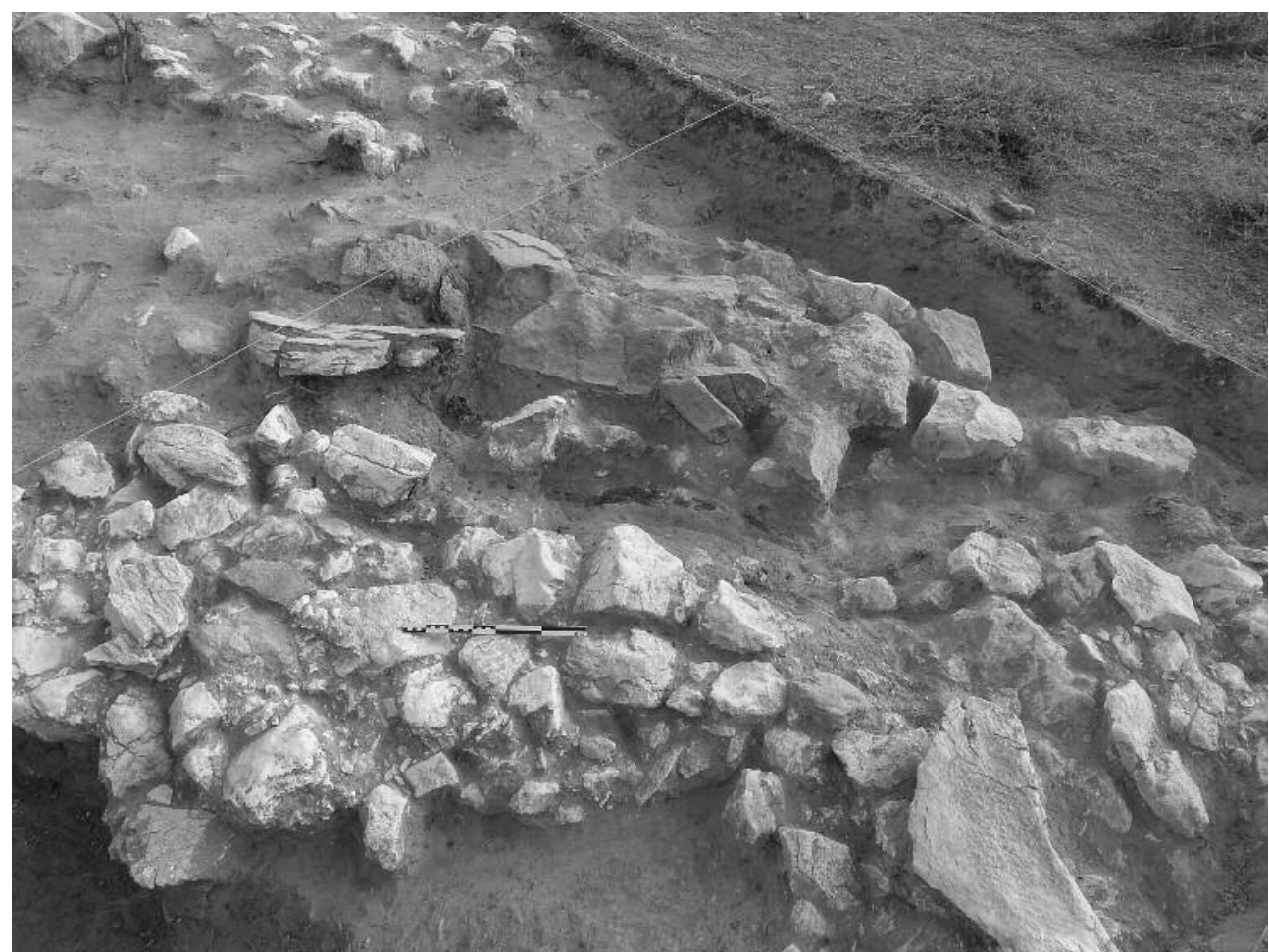

Fig. 2a : Vestiges de la muraille du Fer (Porsuk III) en M06. Vue vers le Nord.

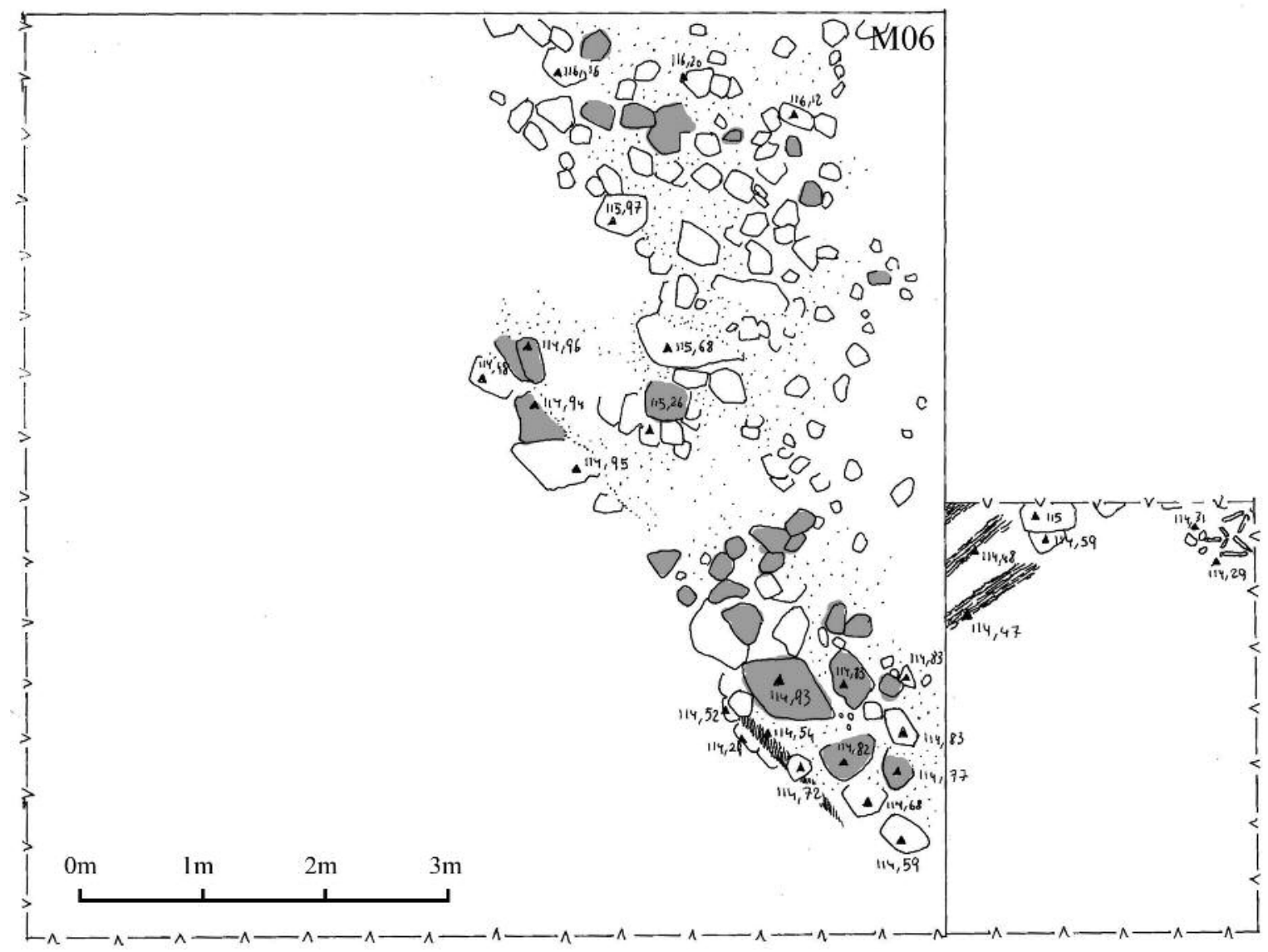

Fig. 2b : Plan des vestiges de la muraille du Fer (relevé Alexis Beyer). 


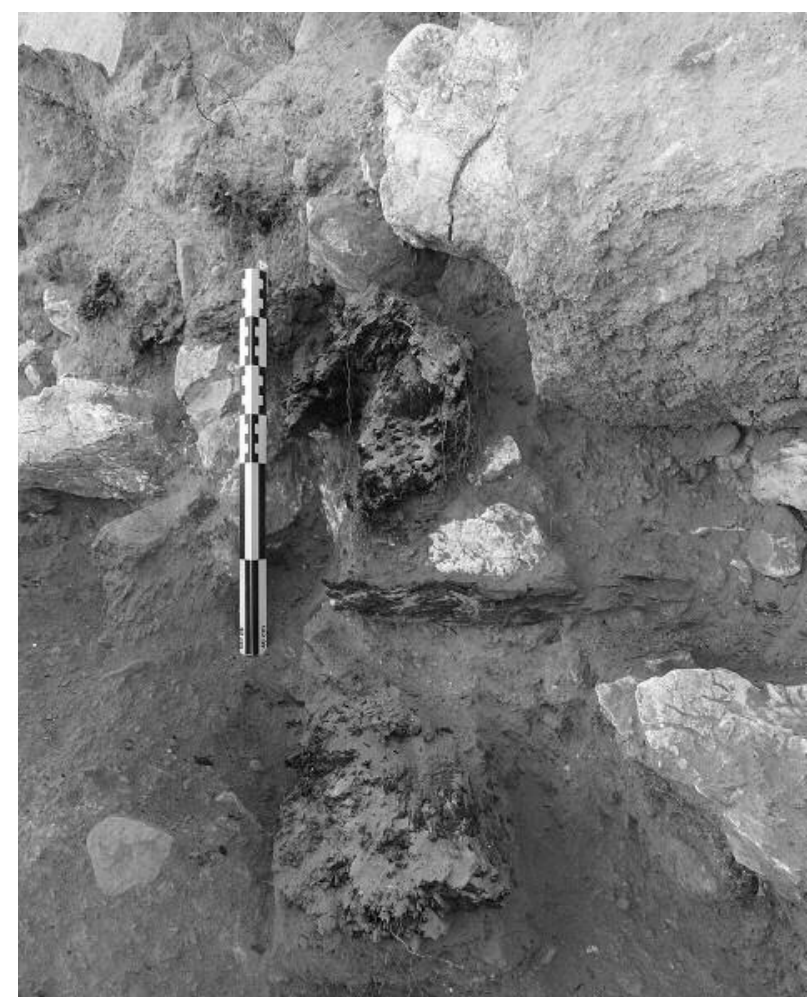

Fig. 3 : Restes d'un système de boutisses et longrines dans le mur du Fer. seulement (Fig. 5 et 6), a montré que nous étions en fait en présence d'une série de sépultures. Ces tombes appartenaient sans doute à une nécropole tardive, limitée à cette pente sud de la butte du chantier II, regardant vers les villages du piémont du Taurus. C'est l'aspect très disloqué des restes du rempart, proches de la surface, qui a empêché le repérage précis des fosses.

\section{Le niveau Porsuk V (Bronze Récent)}

Très rapidement, sous les pierres de la muraille du Fer de Porsuk III - le niveau IV de Porsuk, Fer Ancien, très limité, n'était pas fortifié -, sont apparus $(\Delta 115,15)$ les vestiges de la superstructure de briques cuites par l'incendie, dans une terre briqueteuse rubéfiée, d'une tour du niveau V. Le plan mis au jour n'est que partiel, car le bâtiment s'enfonce encore passablement dans la paroi nord, en amont. Mais le plan (Fig. 7a-b et 8) est conforme à ce que la tour rectangulaire des carrés $\mathrm{J}-\mathrm{K} / 04-05$ avait révélé précédemment pour cette période ${ }^{5}$ : deux salles allongées dans l'axe des courtines, étroites (un peu plus de $1 \mathrm{~m}$ de large) et parallèles, séparées par un mur de briques (03864, modules de 60 x 40 $\mathrm{cm}$ et demi-briques) passablement dégradé dans sa

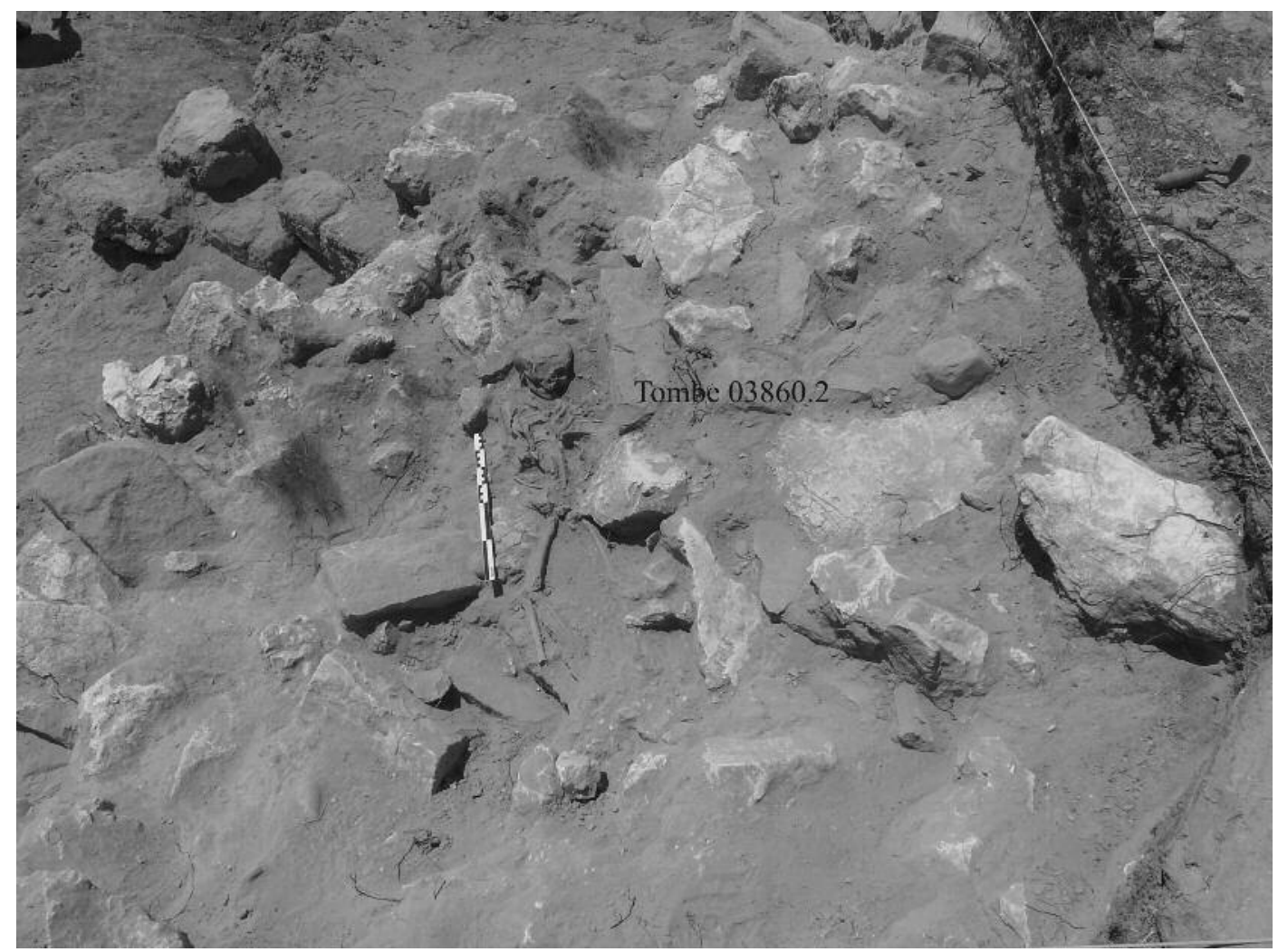

Fig. 4 : Tombe d'enfant (03860.2) parmi les pierres du mur du Fer. Vue vers l'Ouest.

5) Beyer, Karavul, Laroche-Traunecker et Tibet 2015 : surtout 276, fig. 1. 


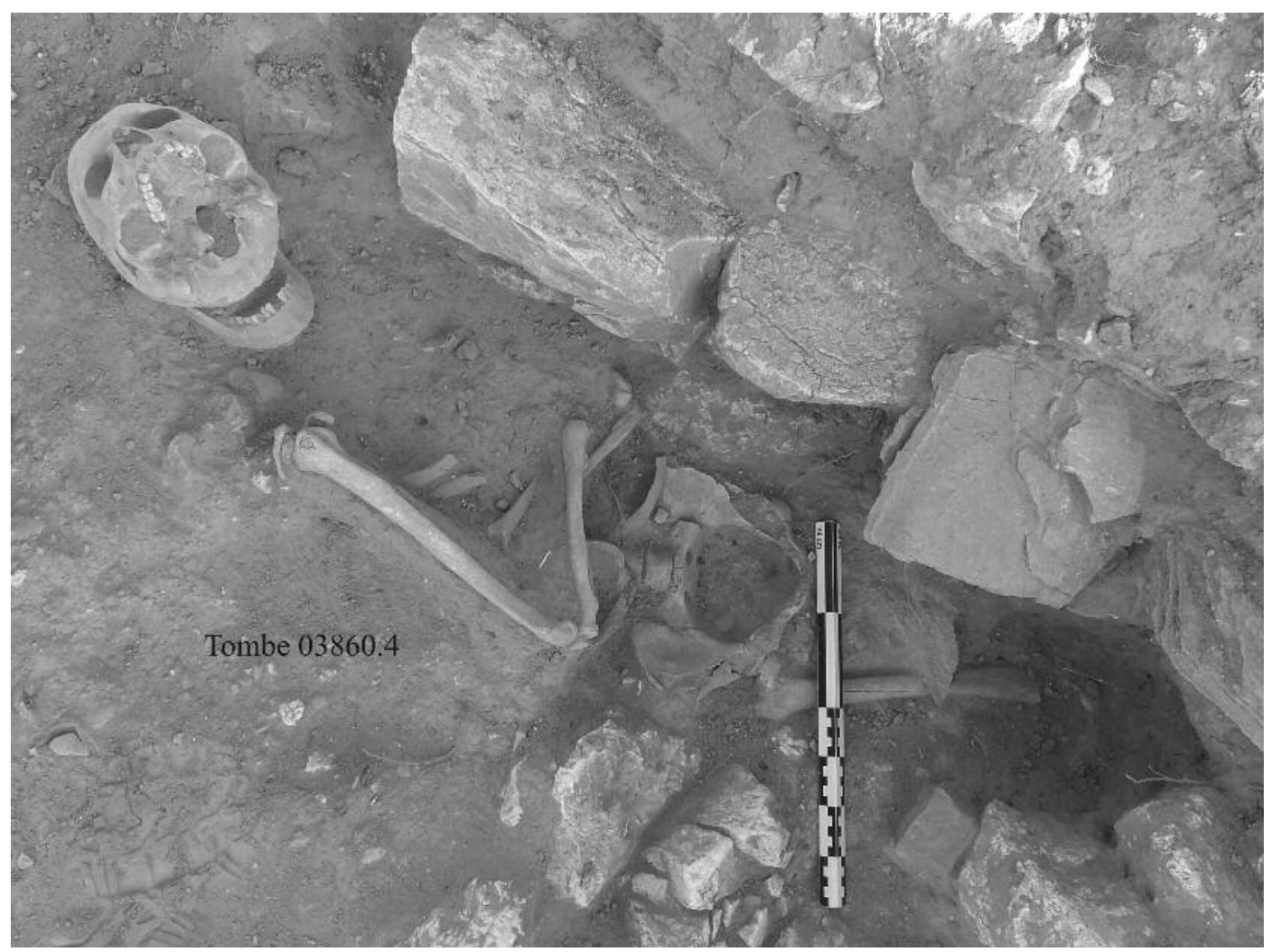

Fig. 5 : Tombe d'adulte (03860.4) dans le mur du Fer. Vue vers le Nord-Ouest.

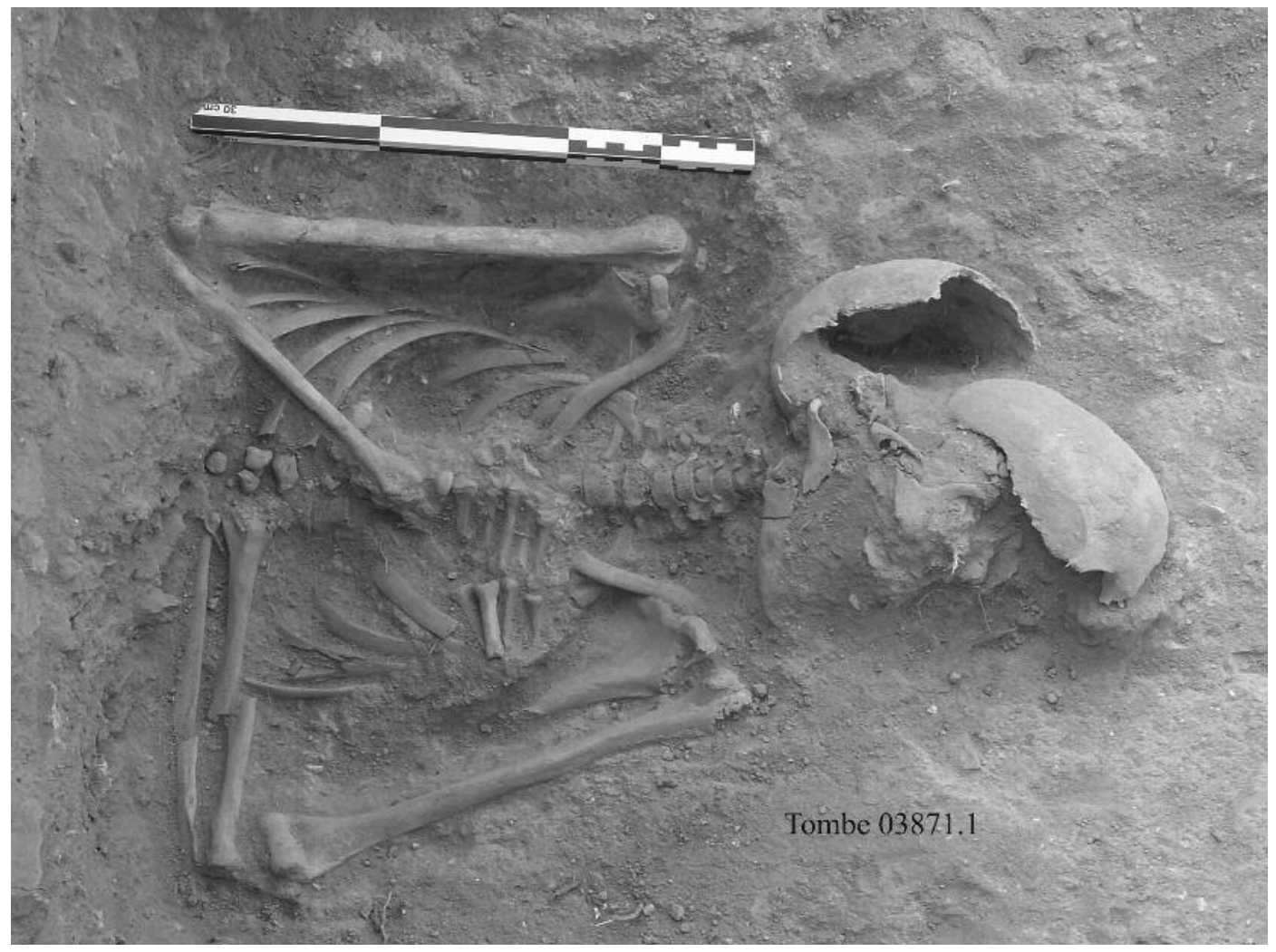

Fig. 6 : Squelette 03874.1 partiellement dégagé en M07. Vue vers le Sud. 


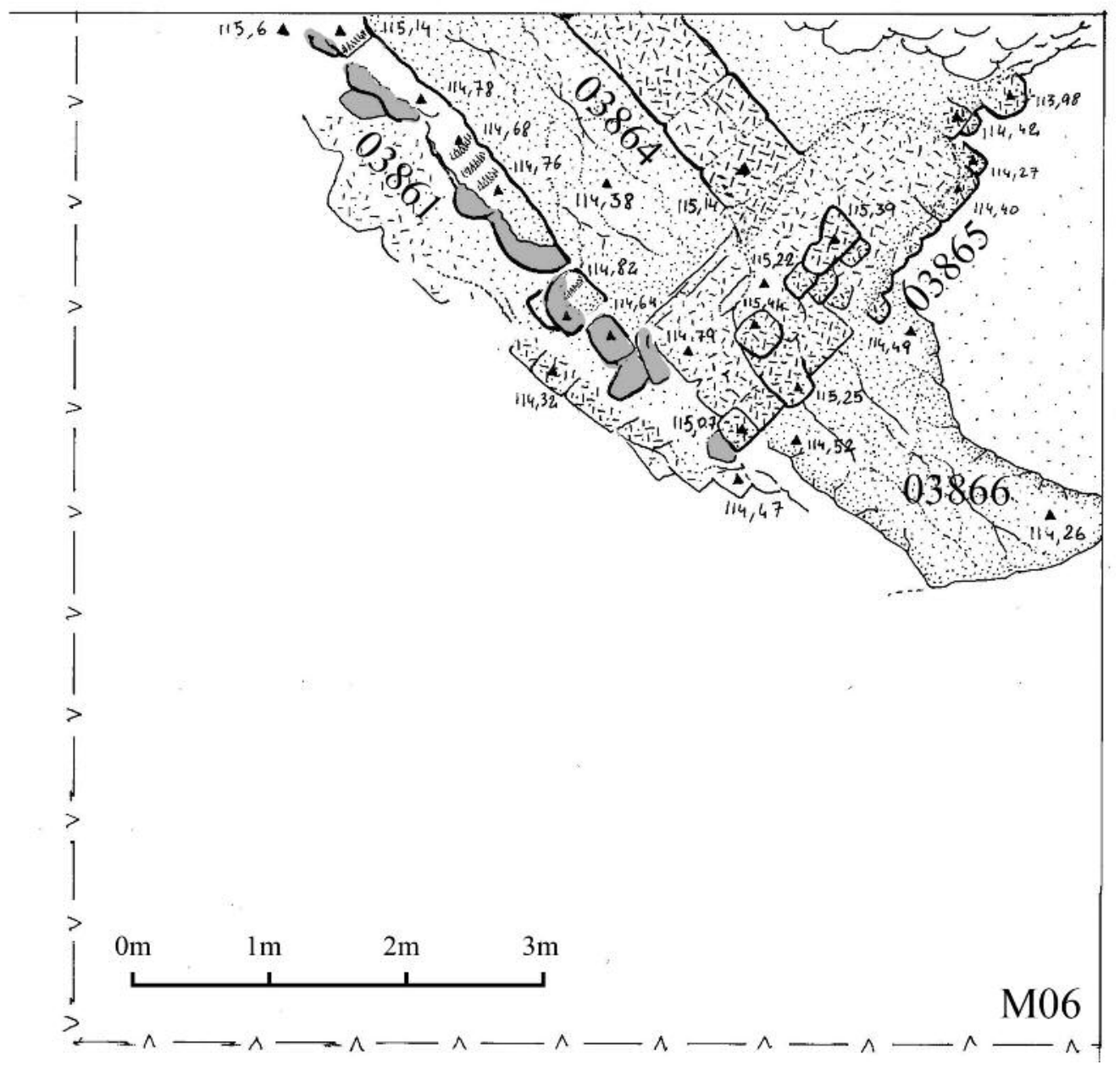

Fig. 7a : M06. Plan du niveau V (A.B.).

partie basse, ayant souffert de l'incendie dont les fortes traces noires sont encore bien visibles en paroi nord (Fig. 10, en haut). Le relevé partiel de la paroi nord du carré M06 (Fig. 9a) montre la succession des niveaux III, dont les pierres plongent profondément du côté est, et $\mathrm{V}$ dont les vestiges du mur de briques 03964 n'étaient plus très lisibles. C'est contre ce mur et dans cette paroi nord qu'a été opéré le prélèvement d'une tranche d'une belle poutre carbonisée (Fig. 9b, 03864.2) destiné à une analyse dendrochronologique $^{6}$.

Le mur de la façade externe (03861, sud-ouest) avait fortement souffert, et c'est surtout son socle de pierres qui était encore bien en place avec, à la base de la superstructure de briques, quelques traces de logement de petites boutisses de bois. Le mur s'appuyait sur les vestiges de la superstructure de briques du niveau inférieur (VI), avec un léger décalage dans l'orientation (Fig. $7 b$ et 10 ). Le mur 03865, passablement dégradé lui-aussi, surtout à son extrémité nord, est plus épais $(1 \mathrm{~m}$ env., et conservé sur $1 \mathrm{~m}$ de hauteur). Il représente le montant nord-ouest de la porte recherchée, car au Sud-Est, la fouille a permis de retrouver les restes d'un sol argileux (03866), lui-aussi cuit par l'incendie, mais un sol extérieur (Fig. 8, 10 et 11), celui d'une porte de la ville du niveau $\mathrm{V}$, ou plus précisément son porche, avec un assez fort pendage vers l'aval $(\Delta 114,49$ à 114,25 sur une distance de $2,50 \mathrm{~m})$ et une partie nord éventrée par l'installation des

6) Cette poutre circulaire, de $22 \mathrm{~cm}$ env. de diamètre, comportait encore son écorce, ce qui est particulièrement précieux pour ce type de technique de datation. Le fragment était destiné à l'équipe américaine de Peter Kuniholm, spécialiste de la dendrochronologie anatolienne, qui avait par le passé réalisé un nombre important de datations pour notre mission. Malheureusement ce prélèvement, tout comme deux autres fragments de bois destinés à des analyses $\mathrm{C}_{14}$, n'a pas eu cette année l'autorisation d'exportation de la part du musée. On ne désespère pas de pouvoir obtenir ces autorisations par la suite... 


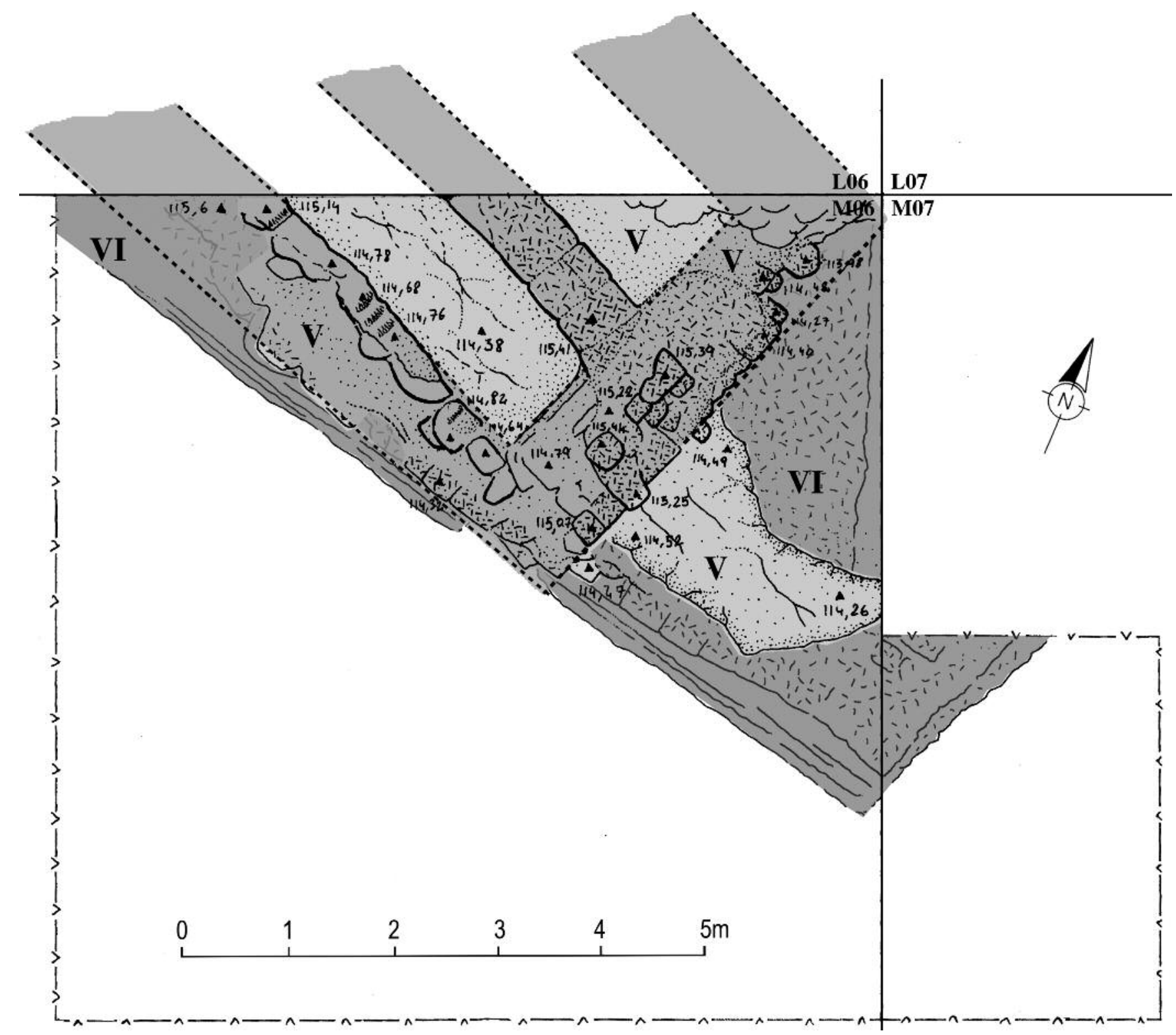

Fig. 7b : M06. Superposition des plans des niveaux V et VI (F.L.-T.).

premières pierres du mur du Fer. Au Sud-Est, la pénétration très profonde de ces pierres du Fer ne laisse guère d'espoir de retrouver les vestiges de la tour du niveau $\mathrm{V}$ qui faisait le pendant de la nôtre. $\mathrm{Au}$ moins sait-on que l'intervalle entre les deux tours dépassait les $2,50 \mathrm{~m}$.

On regrettera que les sols de ce niveau aient été entièrement vides de tout matériel archéologique susceptible de permettre une datation précise de cette phase. Dans l'état actuel du dégagement, on ne peut donc s'appuyer que sur les restes de poutres carbonisées de la couche de destruction à l'intérieur de la tour.

\section{Le niveau initial Porsuk VI (début du Bronze Récent ou fin du Bronze Moyen)}

La tour du niveau $\mathrm{V}$ s'appuyait directement sur les vestiges de celle du niveau VI, avec le décalage déjà mentionné et une différence essentielle : sous le sol du porche du niveau $\mathrm{V}$, la tour inférieure se poursuit vers le Sud-Est jusqu'à sa limite repérée dans l'extension M07 (Fig. 7b, 12), même si ce nouveau montant de la porte de ville a aussi beaucoup souffert de l'érosion et de l'installation du mur du Fer (Fig. 13). Nous n'avons pu dégager que la partie supérieure de son élévation de briques. 


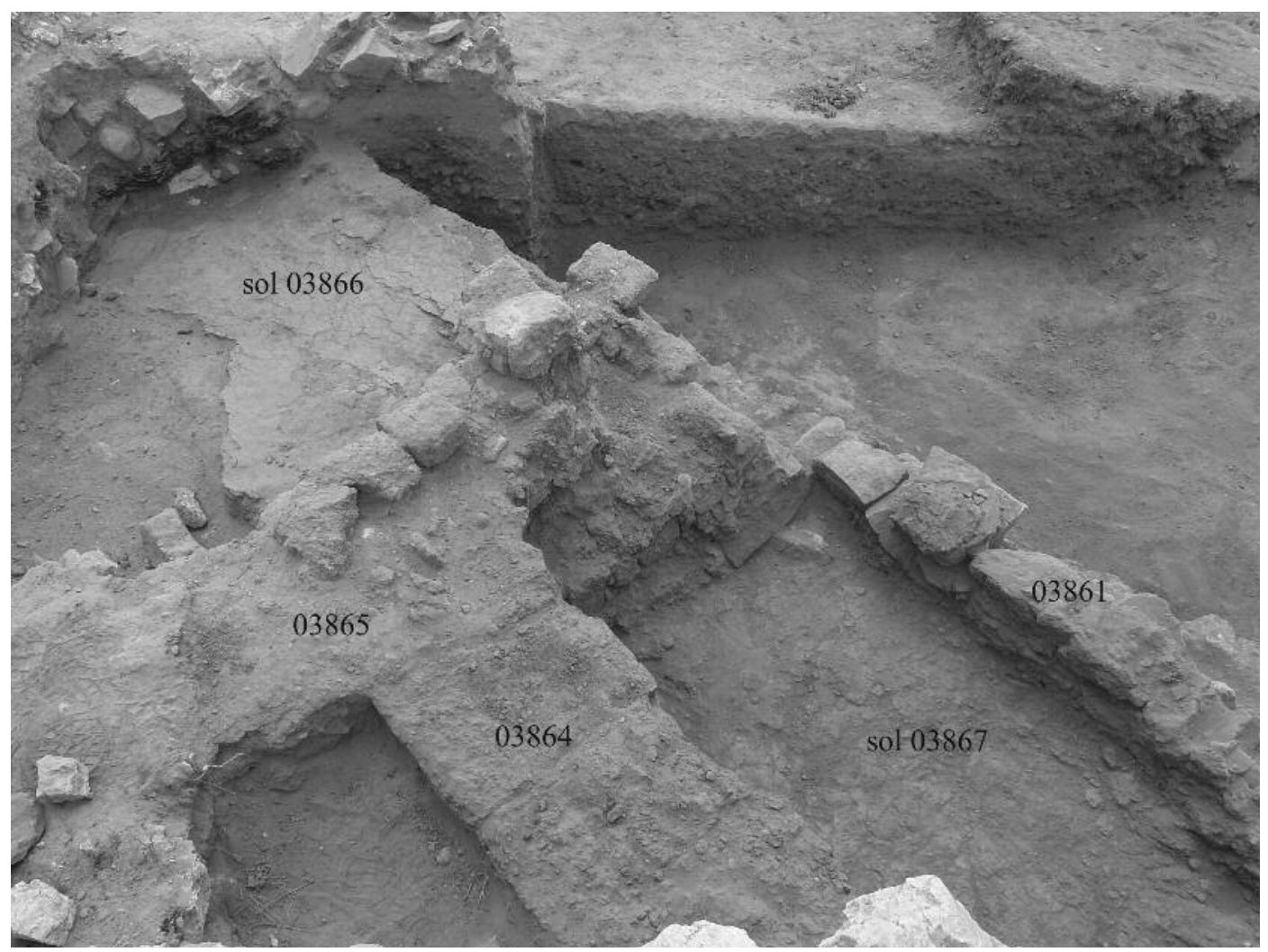

Fig. 8 : Restes de la tour du niveau $V$ et du sol du passage. Vue vers le Sud.

La longueur de la façade externe sud-ouest, de 7,50 m env., a pu être mise en évidence dans le périmètre de la fouille. La largeur dégagée avoisine les $5 \mathrm{~m}$, mais on ne sait pas à l'heure actuelle, dans les limites du sondage, où et comment la tour s'accroche au rempart. La hauteur conservée est impressionnante (Fig. 14-15), avec plus de 5, $40 \mathrm{~m}$, surtout si l'on tient compte du fait que la fouille n'a pu encore atteindre la base du soubassement de pierres de l'édifice, faute de temps et en raison de la dangerosité du sondage profond, en tranchée opérée le long de la façade, la partie nord-ouest étant le secteur où la fouille a pu être menée le plus profondément, avec un système de paliers successifs. La hauteur dégagée du soubassement de pierres de grès est pour l'instant de 2,10 m env., celle de la superstructure conservée de briques de $3,30 \mathrm{~m}$. Sur le relevé de l'élévation de la façade, Fig. 15, on voit à gauche que l'angle nord-ouest de la tour a été fortement abîmé jusqu'au soubassement de pierres et les restes de la couche de destruction y sont bien visibles. Celle-ci a été en partie conservée sur place après mise au jour, car sa structure ici particulièrement compacte et durcie par le feu permettait de consolider l'extrémité du mur, en vue de la conservation de l'ensemble jusqu'à présent dégagé.

$\mathrm{Au}$ fur et à mesure de l'avancée de la fouille, la fragilité de la façade nous a en effet préoccupés : les briques de la superstructure ou les pierres du soubassement présentaient à plusieurs reprises de forts pendages vers l'intérieur de la tour, et donc un certain nombre de porte-à-faux (Fig. 16). Cette fragilité a rendu nécessaire la pose de poutres (de peuplier) à certains emplacements des longrines placées à l'origine, à intervalles plus ou moins réguliers, dans la façade (toutes les 6 à 8 assises de briques environ). Dans la partie supérieure du mur, côté nord-ouest, on peut mesurer par exemple, grâce aux traces laissées dans l'argile, l'existence d'une longrine de bois équarri de $20 \mathrm{~cm}$ env. de côté. C'est la première fois, à Porsuk, que les traces étaient suffisamment explicites pour pouvoir faire cette observation : une poutre équarrie pour permettre d'éviter la chute de poutres de section circulaire qui auraient pu plus facilement rouler et tomber ${ }^{7}$. Sur cette question des chaînages de bois, on notera que dans

7) Les consolidations et restaurations faites d'urgence par nos soins ont utilisé des portions de troncs de peuplier non-équarries, avec l'espoir que ces interventions, visibles sur certaines photographies, seraient suffisantes. 


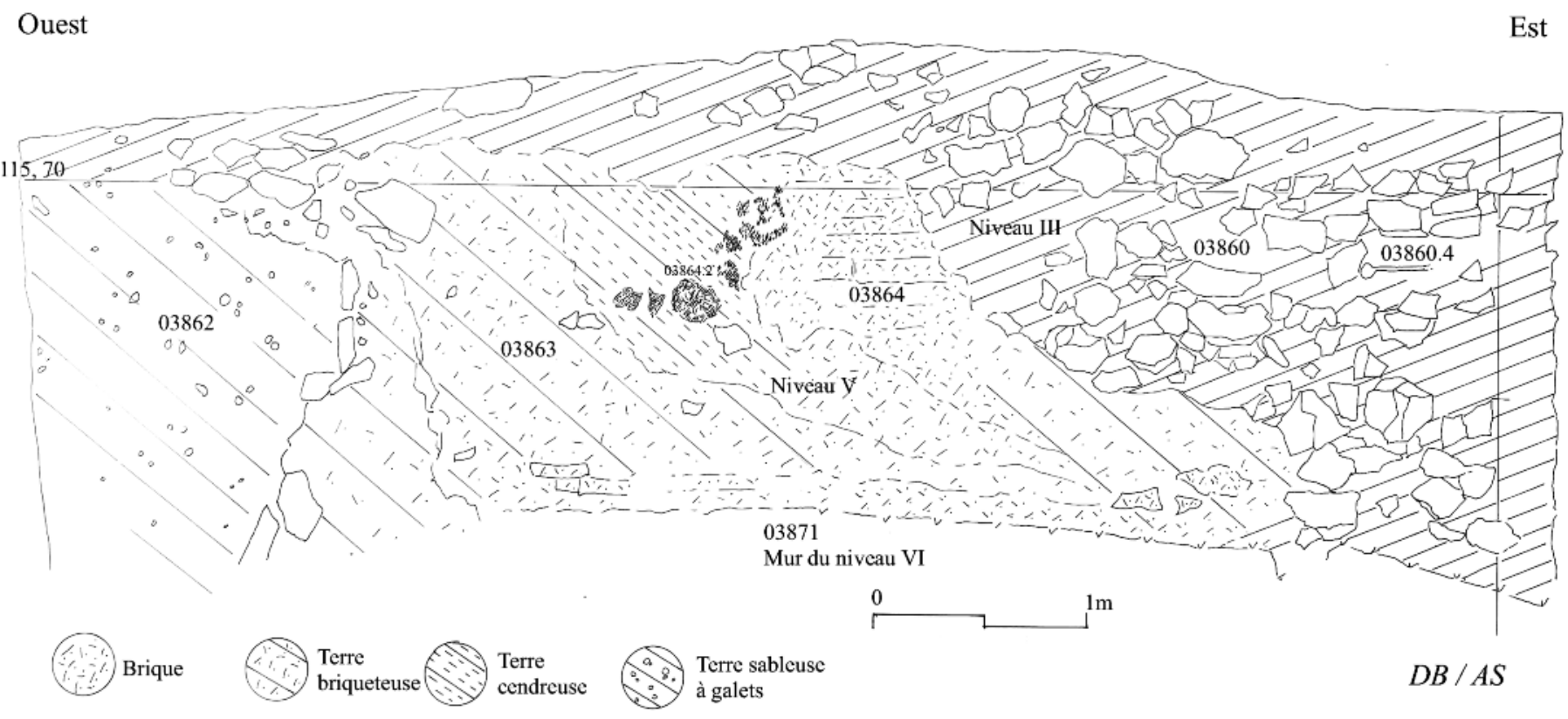

Porsuk 2015- Chantier II Sud. Carré M06: paroi Nord, partie Est

Fig. 9a : Paroi nord de M06 (partie est), au-dessus des vestiges de la tour du niveau VI (relevé D. Beyer et A. Signoret).

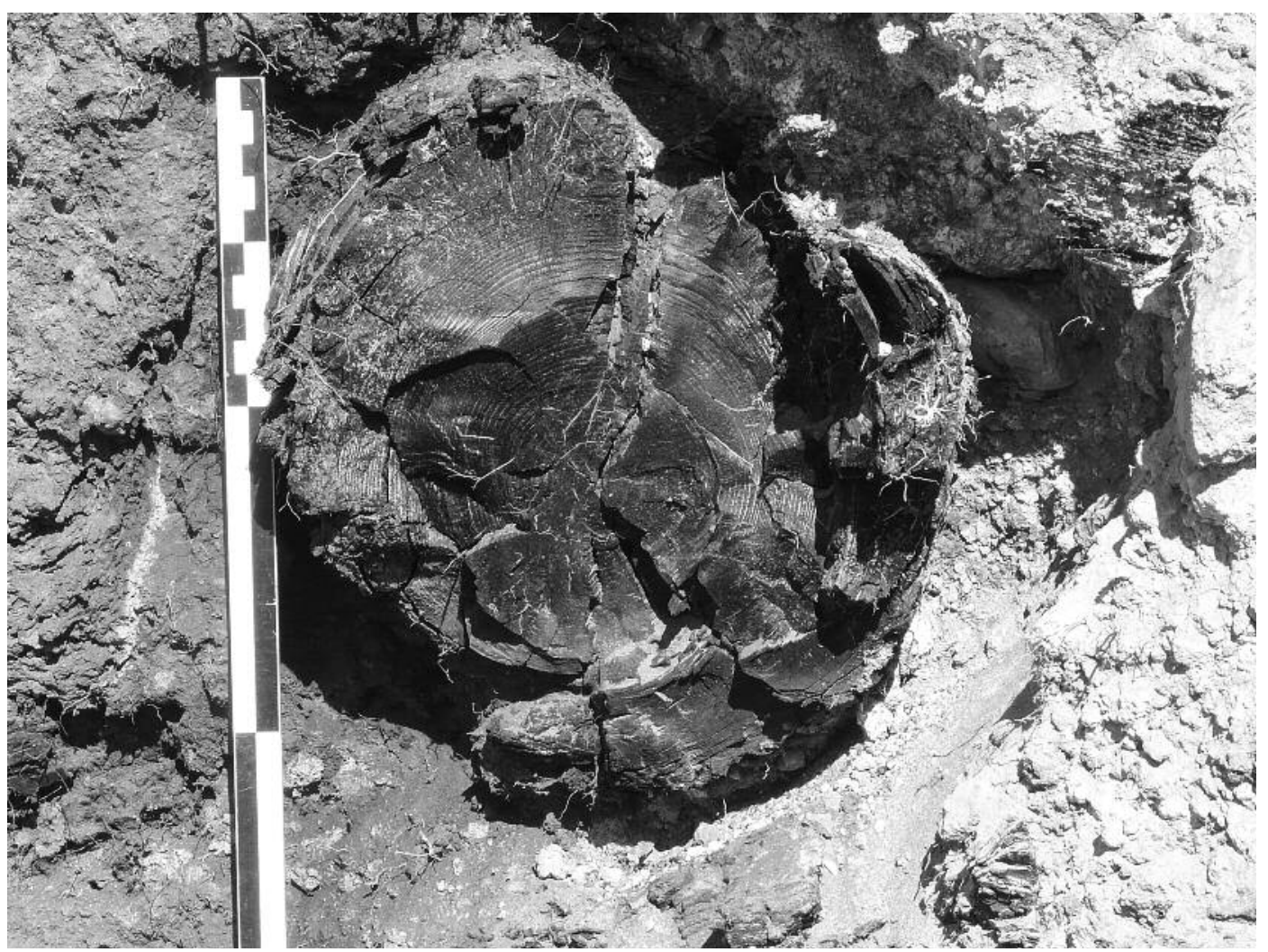

Fig. 9b : Poutre carbonisée dans la paroi nord de M06. 


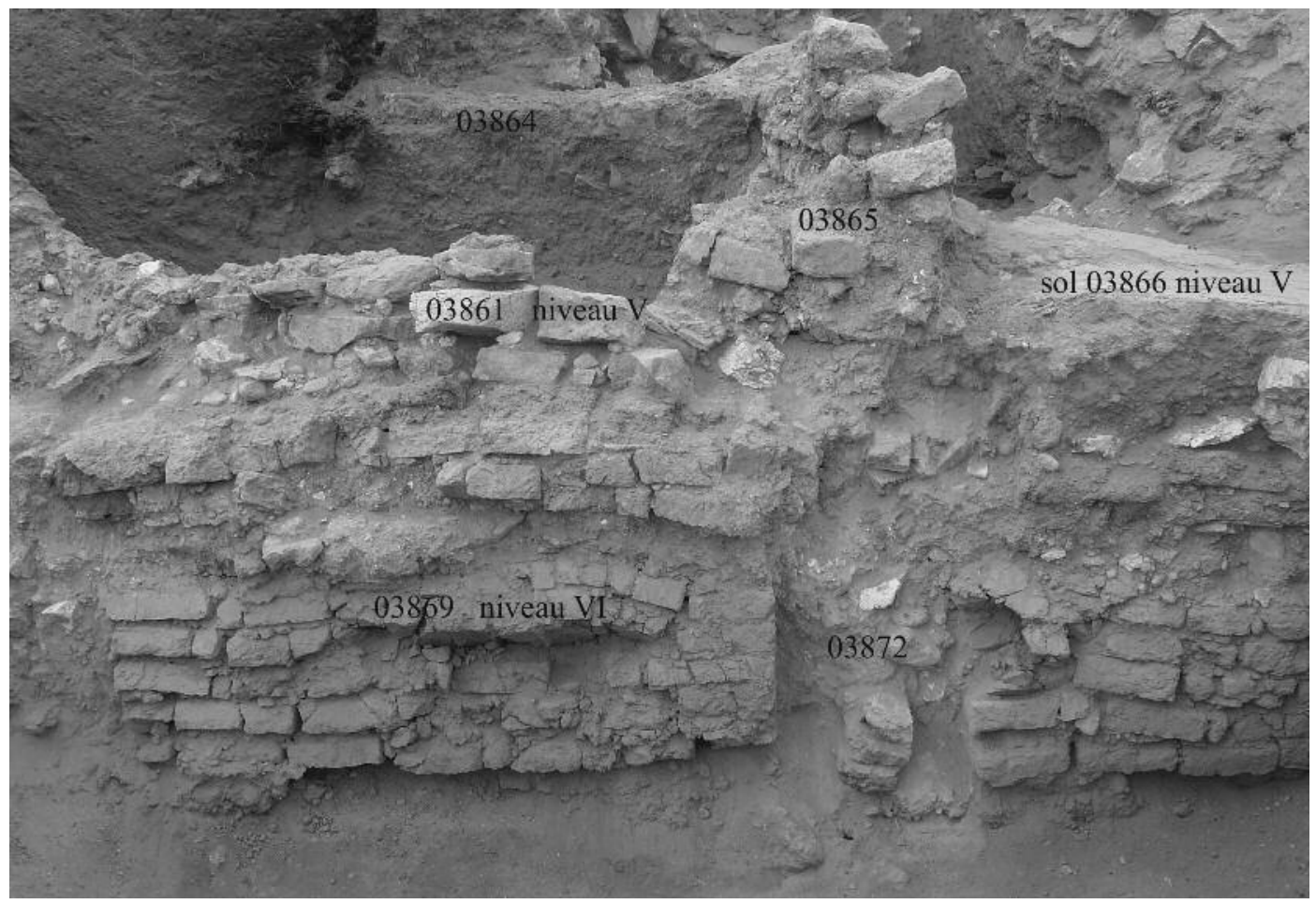

Fig. 10 : M06. Superposition des murs des niveaux V et VI. Vue vers le Nord-Est.

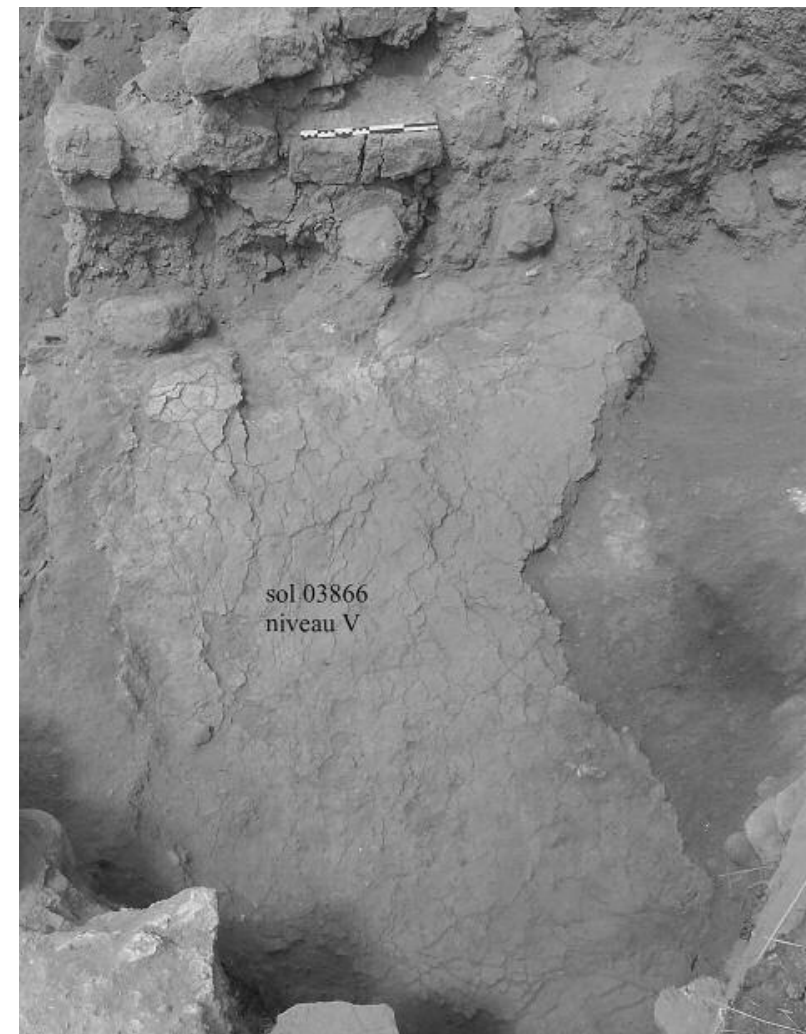

Fig. 11 : M06. Vestiges du sol 03866 de la porte, au pied du mur du niveau V. Vue vers le Nord-Ouest. les parties hautes, aucune trace de bois n'a pu être observée, tant l'incendie était violent, ce que confirme l'aspect parfois calciné des briques. En revanche, dans la partie basse, dans l'intérieur du soubassement de plaques et blocs de grès (Fig. 17), un alignement de boutisses a pu être retrouvé, conservées à l'état carbonisé, mais très pulvérulent, là où le feu a plus rapidement été étouffé par l'accumulation des débris. La violence du feu a pu être attisée dans les parties supérieures, en plus des chaînages de bois, par des ouvrages de bois au sommet du rempart, et le cas échéant par l'incendie d'échelles et de machines de guerre utilisées par les assaillants. Le caractère exceptionnel de cette découverte, dans le contexte de l'archéologie anatolienne du second millénaire, ne permet pas le recours à des parallèles instructifs, car trop rares sont les superstructures de briques suffisamment conservées dans la documentation archéologique. Cette remarque vaut pour d'autres aspects de cette architecture qu'il convient d'examiner.

Le plan de la Fig.12, ainsi que les Fig. 18 et 19, montrent que la tour a été retrouvée entièrement comblée de briques, au moins dans la partie supérieure, à cet égard la seule connue jusqu'à présent, sans que l'on puisse déceler un éventuel parement interne du mur de façade. L'ensemble apparaît alors comparable au massif de la tour triangulaire nord-ouest du chantier II Nord, dégagée lors des premières 


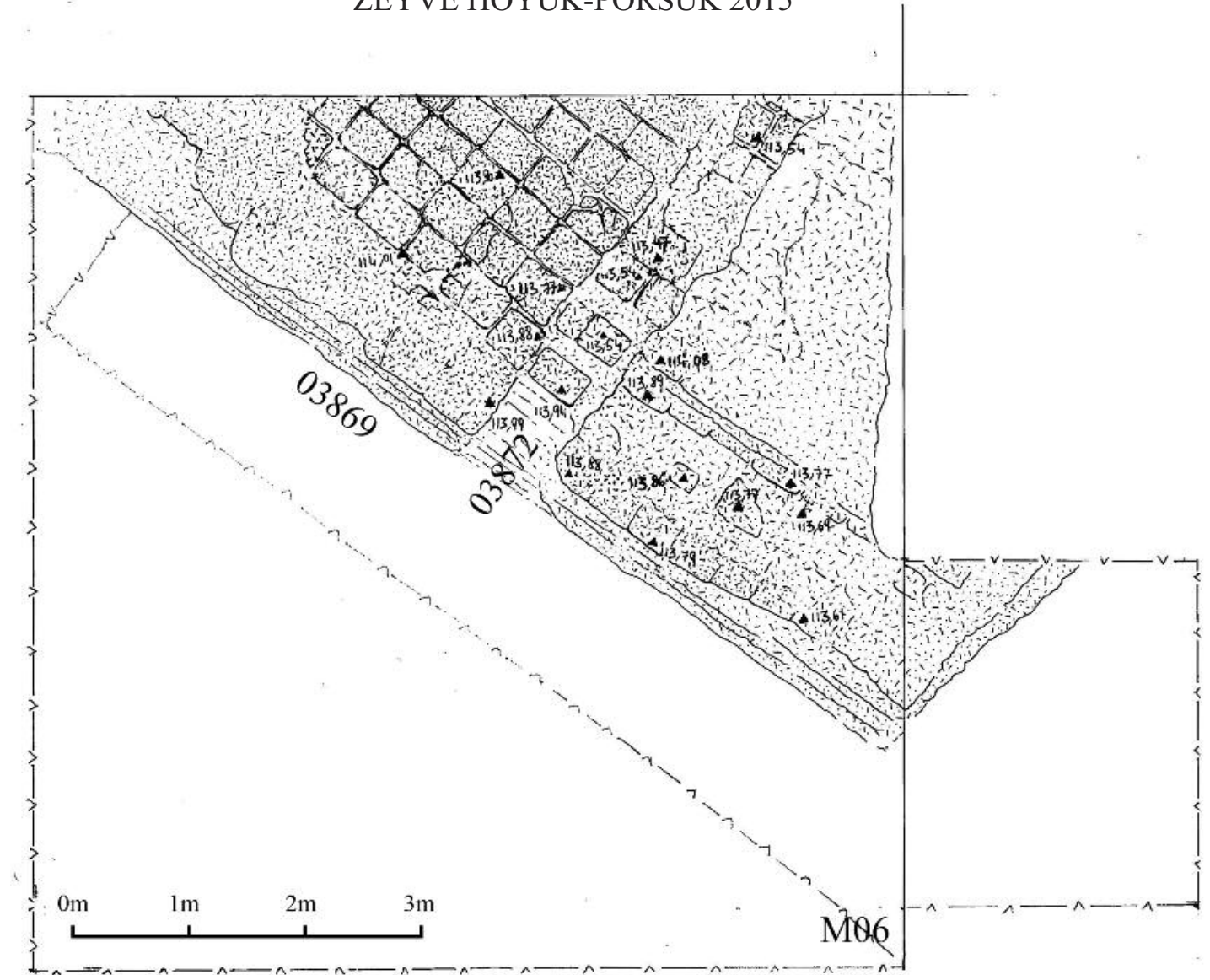

Fig. 12 : M06-07. Plan du niveau VI (A.B.).

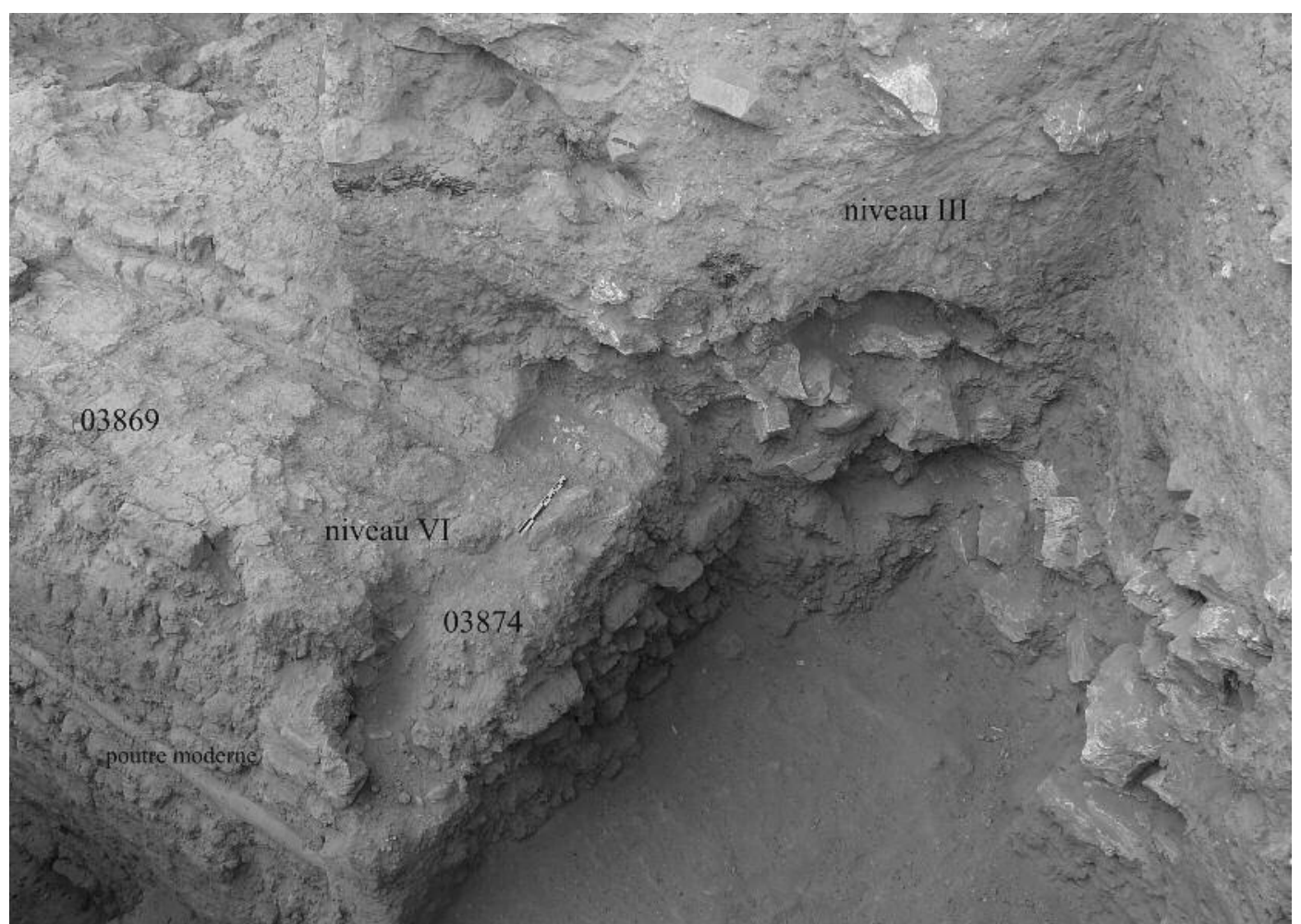

Fig. 13 : M06-07. Extrémité de la tour du niveau VI, avec les pierres de l'installation du Fer. Vue vers le Nord. 


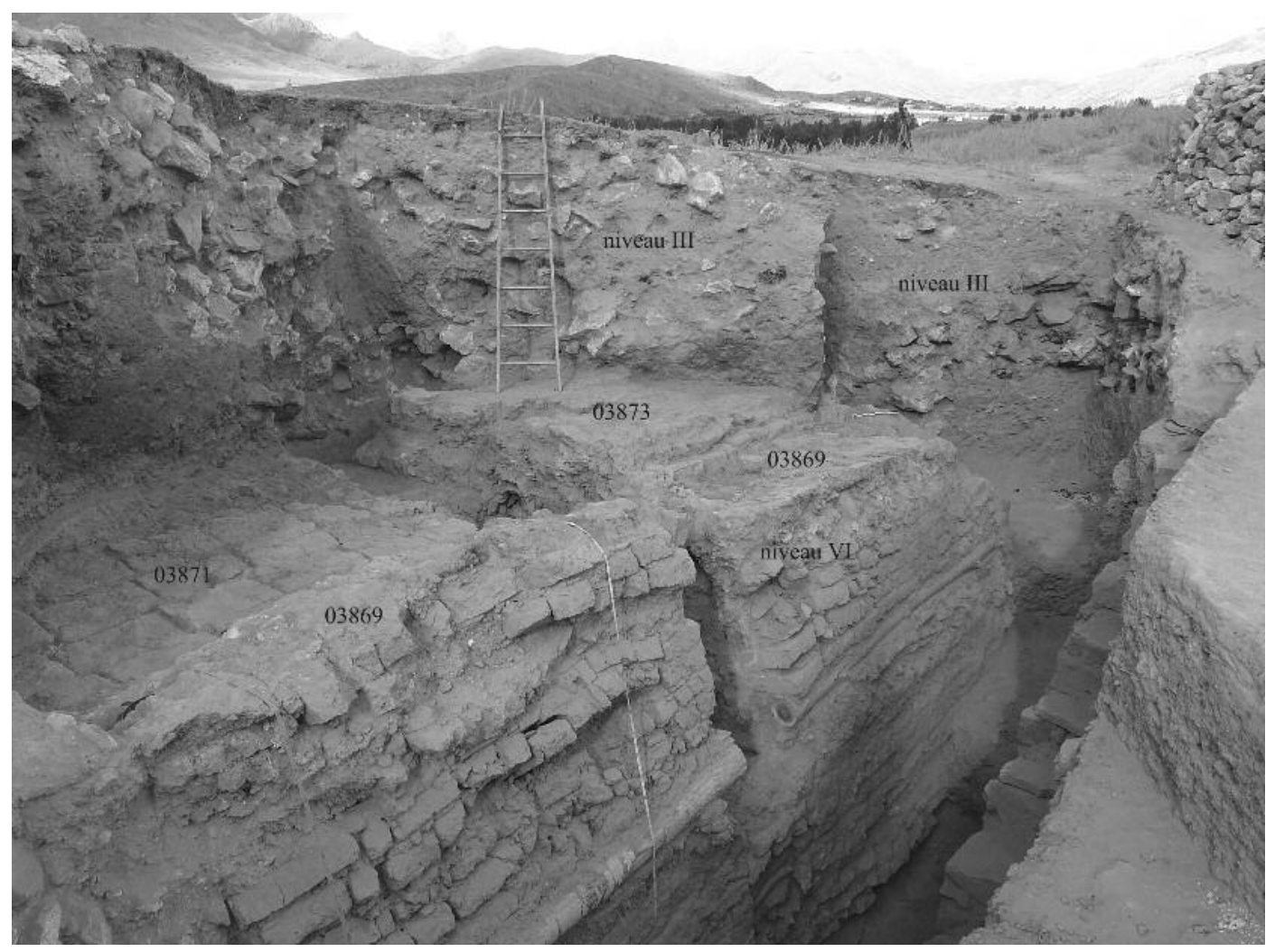

Fig. 14 : Vue générale du chantier de la tour du niveau VI, vers l'Est.

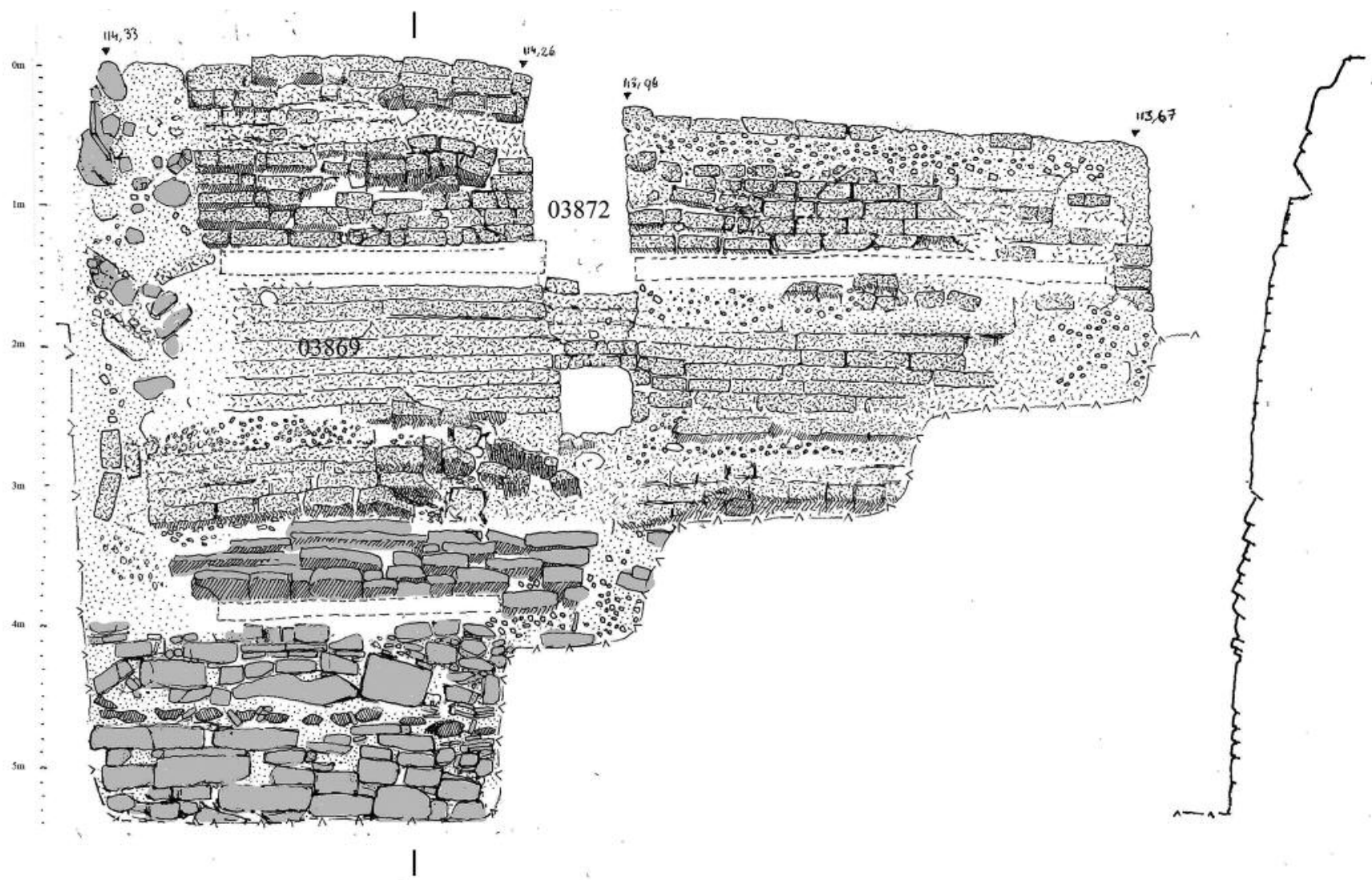

Fig. 15 : Elévation de la façade externe de la tour du niveau VI (A.B.). 


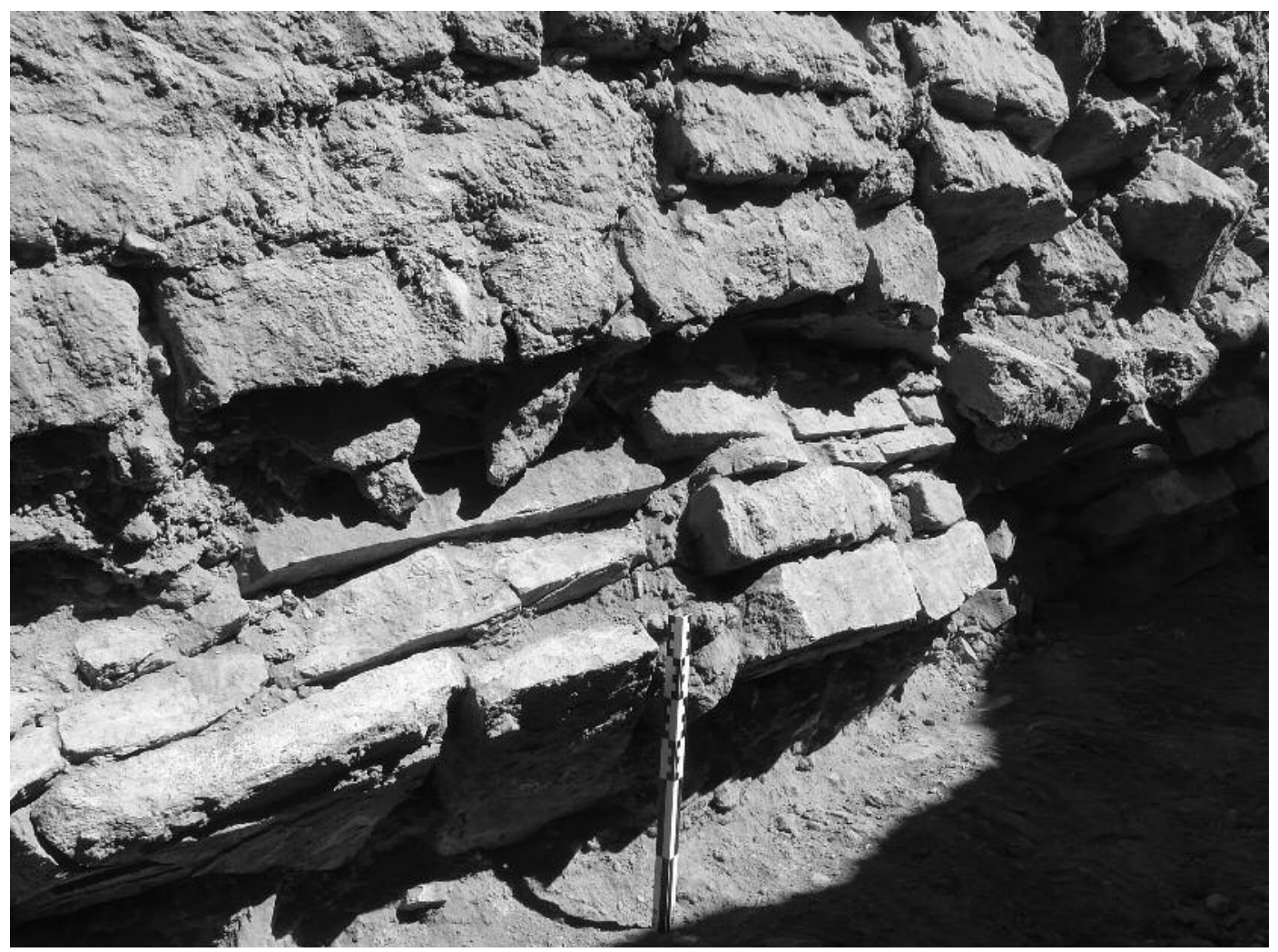

Fig. 16 : Sommet du soubassement de pierres au-dessus du logement d'une longrine. Vue vers le Nord-Est.

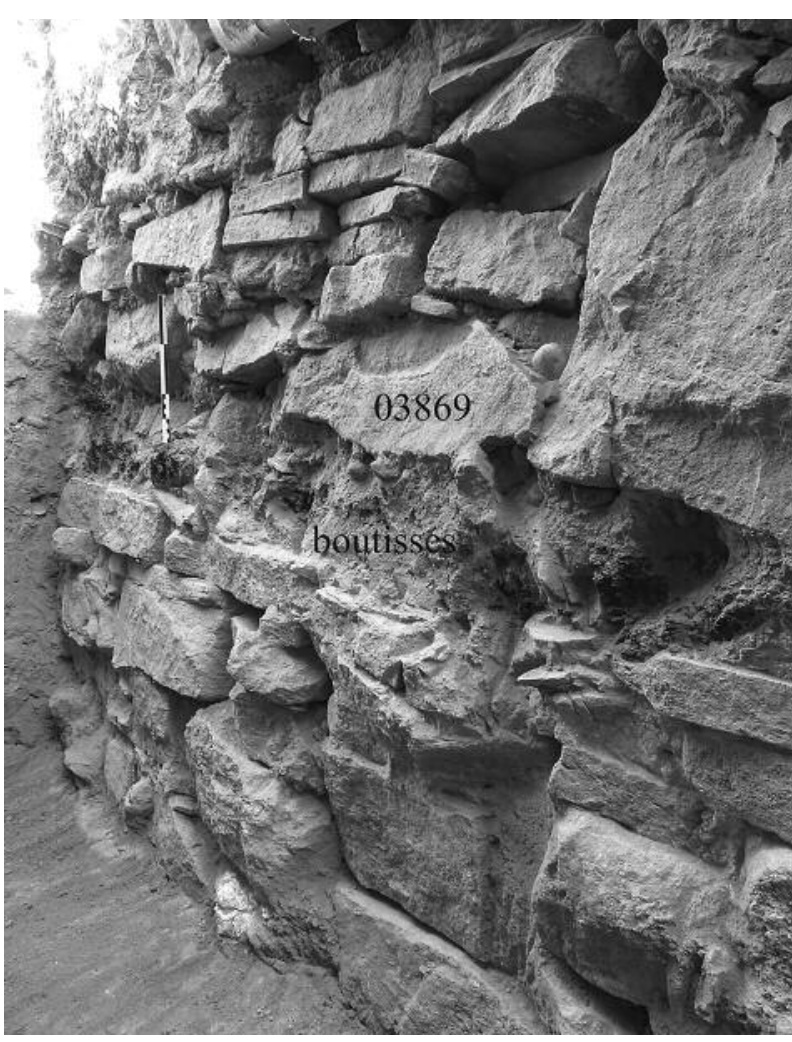

Fig. 17 : Le soubassement de pierres avec boutisses carbonisées. Vue vers le Nord-Ouest.

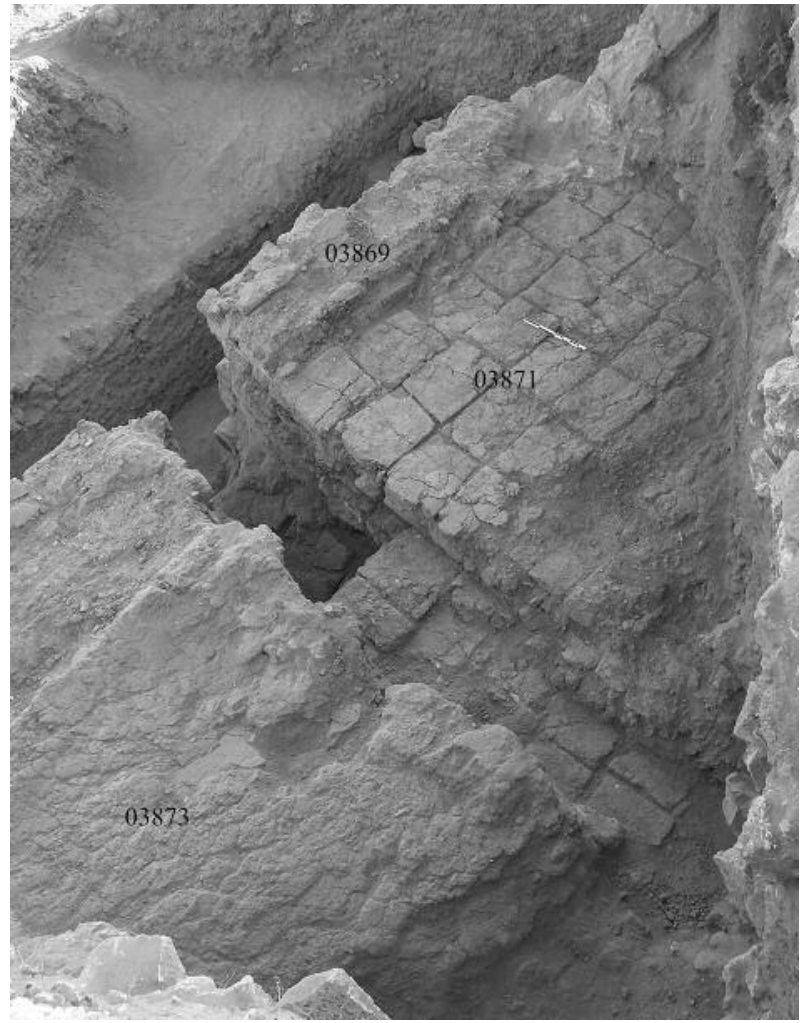

Fig. 18 : Sommet de la tour en M06. Vue vers l'Ouest. 


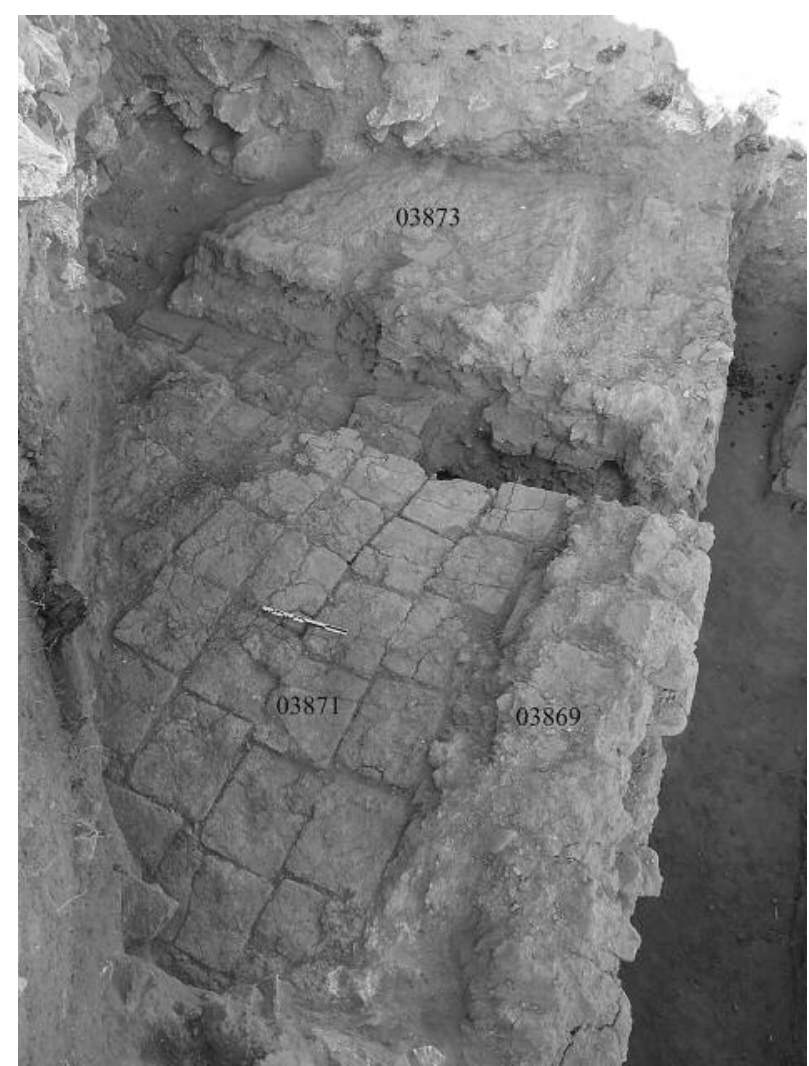

Fig. 19 : Sommet de la tour en M06. Vue vers l'Est.

campagnes de la mission Pelon. Les briques, de module moyen de $45 \times 35 \times 11 \mathrm{~cm}$, étaient particulièrement bien conservées du côté nord-ouest, bien cuites par l'incendie, mais sensiblement moins cuites plus on s'éloignait de la façade externe, dans l'angle nord-est du carré M06, perturbé par l'installation du Fer. De l'autre côté de cette sorte de saignée NordEst/Sud-Ouest 03872, dont il sera question infra, l'aspect actuel de la surface dégagée par la fouille correspond pour l'essentiel à l'existence d'un joint horizontal d'argile, avec empreintes de briques ayant versé vers le Nord-Est, qu'il a été particulièrement difficile d'éliminer car il adhérait fortement aux deux à trois assises de briques sous-jacentes, rendues très solidaires par la violence de l'incendie ${ }^{8}$. On notera ici que l'épaisseur réduite de ces briques (10 à $12 \mathrm{~cm}$ ) est conforme à ce que l'on connaît des briques du niveau VI de Porsuk, alors que celles du niveau $\mathrm{V}$, plus récent, sont plus épaisses (env. 12 à
$13 \mathrm{~cm}$ ), ces différences s'observant facilement en façade.

$\mathrm{Au}$ centre approximatif de la tour, cette sorte de saignée Nord-Est/Sud-Ouest (03872) a posé et pose encore bien des difficultés d'interprétation. C'est l'emplacement où, bizarrement, avait été juste audessus construit le mur 03865 du niveau V. Dès le dégagement du sommet conservé de la tour du niveau VI, cet espace large de $65 \mathrm{~cm}$, orienté Nord-Est/SudOuest, semblait marquer une séparation entre les deux portions construites de la tour. Sur la façade externe, cet espace apparaissait comblé de débris de la couche de destruction, avec fragments de briques et gros galets (Fig. 20). De part et d'autre, des montants soigneusement appareillés donnaient l'impression que l'on était en présence d'une sorte de petite poterne aménagée dans l'épaisseur du mur. Mais au cours de la progression vers le bas, cette hypothèse a été abandonnée, car cet espace s'interrompait sur une épaisseur de plusieurs assises de briques (Fig. 15 et 21) et d'autre part, le sondage opéré dans la moitié externe de ce "couloir" a montré que l'intérieur était comblé de briques, de manière très hétérogène, certaines apparaissant comme tombées, d'autres au contraire faisant visiblement corps avec le remplissage de briques des deux côtés (Fig. 21), au moins jusqu'à la profondeur atteinte, d'env. 1,50 m.

Le problème s'est compliqué lorsqu'est apparue, 6 assises plus bas, une nouvelle ouverture, mais plus étroite $(60 \mathrm{~cm})$, et grossièrement carrée, que nous n'avons pas eu le loisir d'explorer en profondeur, car il a fallu immédiatement étayer et combler, la maçonnerie s'effondrant rapidement (Fig. 15 et 21). En attendant que la réflexion puisse se nourrir encore de l'examen d'éventuels parallèles, et en attendant que des recherches ultérieures puissent apporter des informations supplémentaires - par exemple sur la situation du côté interne du mur -, on peut se demander si un tel dispositif n'avait pas de rapport avec la nécessité de prévoir des sortes de drains dans la maçonnerie ? On peut penser à cet égard, mais avec grande prudence, et toutes proportions gardées, à des drains-gouttières attestés dans les façades externes de certaines ziggurats ou autres grandes constructions mésopotamiennes en briques (Uruk, Eridu, l'E-Babbar de Larsa...). Reconnaissons pour l'instant que cette hypothèse rencontre quelques difficultés si l'on tient compte de la situation retrouvée.

8) Cette remarque est importante dans la mesure où l'on pouvait s'interroger sur l'utilisation éventuelle de briques cuites ou semicuites par les bâtisseurs des remparts de Porsuk, ce qui aurait pu expliquer le caractère des briques retrouvées, cuites même dans la masse du mur. Si l'on ne peut guère exclure cette hypothèse, il faut être attentif au fait que les briques paraissent moins cuites en direction de la façade interne et surtout que les divers joints, lorsqu'ils ne tombaient pas en poussière, apparaissaient eux-mêmes cuits. Seul un incendie violent, une fois les briques posées, peut alors être tenu responsable de cet état de fait. 


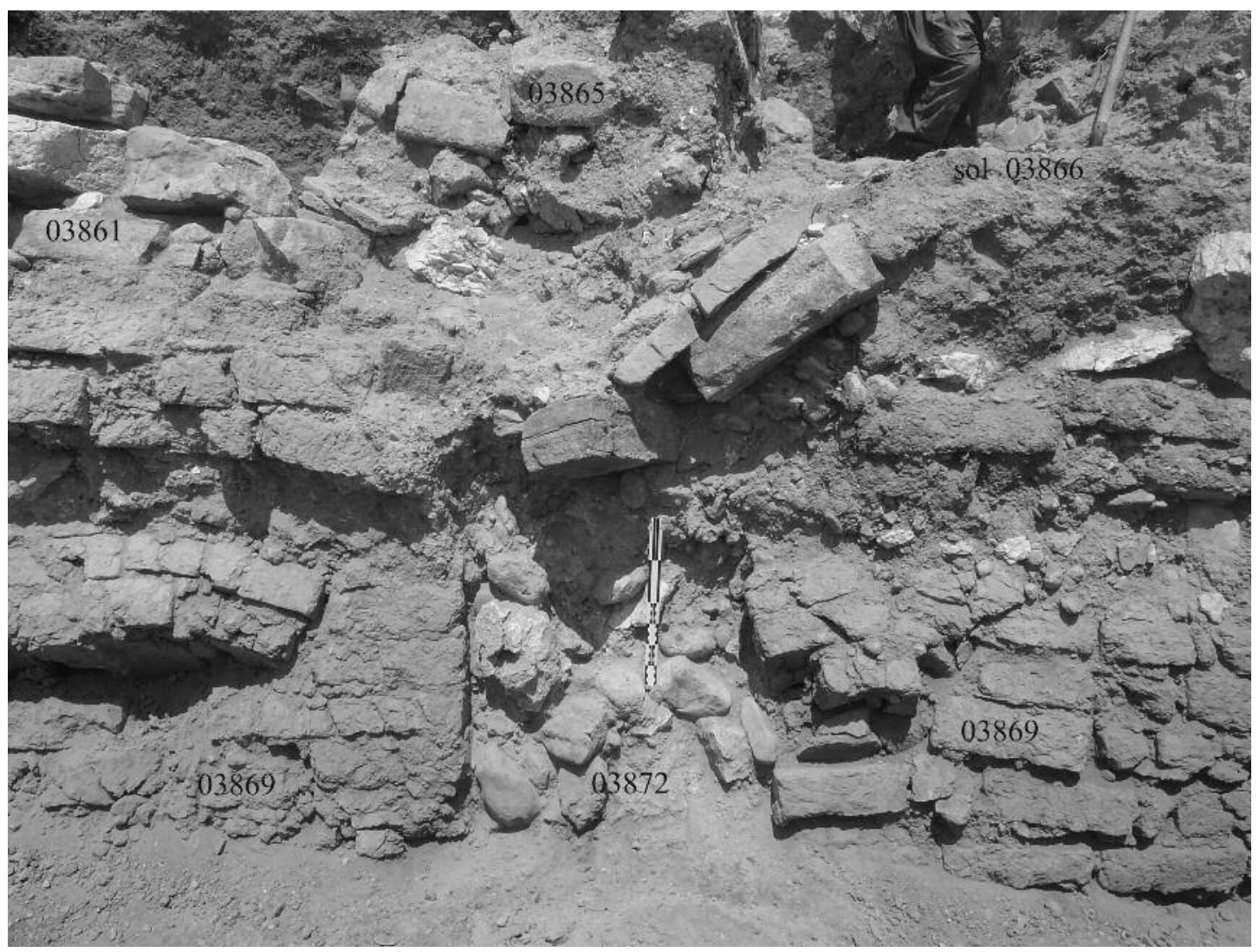

Fig. 20 : Sommet de l'ouverture centrale dans la façade externe. Vue vers le Nord-Est.

A l'intérieur de ce "couloir", l'examen des deux côtés a montré en outre qu'il y avait un affaissement des assises de briques vers le centre, comme si un vide existait en contrebas, ce que semblait montrer déjà le fort pendage, en façade, de certaines briques, mais aussi certaines pierres du soubassement (Fig. 16), comme aspirées par un vide central, une pièce, éventuellement une casemate ? L'ensemble de la tour a-t-il alors été comblé dans un deuxième temps, pour pallier une éventuelle fragilité ${ }^{9}$ ?

Se pose alors également la question de l'existence de cette fameuse "masse métallique importante" repérée par les géophysiciens. Si elle correspond à une réalité - le dialogue avec les géophysiciens, les mêmes ou d'autres, devra être poursuivi sur ce point, car la question dépasse nos compétences -, il y a peu de chances qu'elle puisse être encore au pied de la façade externe de la tour, du côté nordouest, bien exploré par nos soins. En revanche, il reste une possibilité qu'une telle masse subsiste à l'intérieur, à la base de la tour, toujours du côté nord-ouest, à rechercher encore. Le jeu en vaut-il la chandelle ? Sans doute, si l'on considère d'abord que notre programme de recherche s'intéressait aux liens entre l'ancienne cité et l'exploitation minière du Taurus. La "masse métallique mentionnée" pourrait alors apporter sur ce point des informations intéressantes. D'autre part, nous ne connaissons nulle part réellement l'intérieur du dispositif d'une tour du niveau VI, ni d'ailleurs d'aucune tour comparable pour l'Anatolie du second millénaire, voire au-delà. Il conviendrait alors d'étudier la faisabilité, technique et politique, d'une telle investigation, qui impliquerait le démontage, et sans doute le remontage après fouille, d'une partie de la tour.

Aucun matériel n'a pu être retrouvé dans ce niveau. Cela s'explique, au moins le long de la façade externe, par le fait que les bâtisseurs du niveau $\mathrm{V}$ ont comblé l'espace externe de terre à gravillons pour réaménager un dispositif de glacis et d'accès à la porte. La datation de cette architecture militaire du niveau VI, qui s'appuyait probablement, au moins en partie, sur la table de conglomérat du site, se fonde alors sur la comparaison avec les autres

9) On précisera ici que l'intérieur de la tour du niveau VI en J-K/04-04 n'avait pas pu être exploré lors de la campagne de 2012. Le fort pendage des briques de la façade externe vers l'intérieur du dispositif avait déjà été observé. 


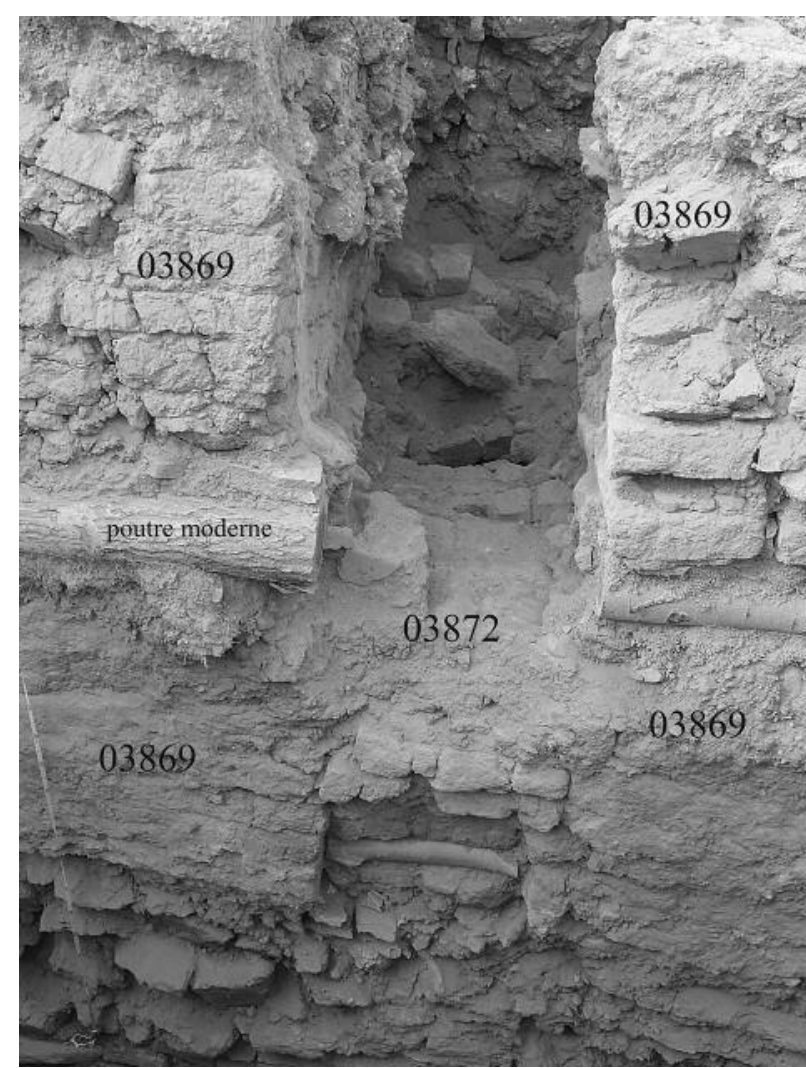

Fig. 21 : Superposition des deux éléments de l'ouverture centrale dans la façade.

secteurs et sur la continuité du rempart de cette partie occidentale du höyük, remontant à la fin du $17^{\mathrm{e}}$ ou au début du $16^{\mathrm{e}}$ siècle av. J.-C. ${ }^{10}$ Peut-être pourra-t-on bénéficier des résultats d'une analyse, en Turquie-même, par thermoluminescence d'une des briques cuites par l'incendie de la tour de ce niveau initial.

\section{LE CHANTIER IV NORD}

(I. Chalier, F. Kirner)

\section{Niveau 1 et 2 en $\mathbf{H} 40$}

Cette année, il était prévu de continuer la fouille en extension jusqu'à la limite nord du carré H40 (Fig. 22a) pour compléter les plans de l'espace formé par les murs 01628,01636 et 01718 . Nous avons ainsi mis au jour la suite du dallage en grès (01717) appartenant au niveau 1 du site (Fig. 22b) et découvert en 2013 ainsi qu'un important mur de grès et de gypse 01759 orienté Est-Ouest (Fig. 23). La largeur du dallage au Nord est supérieure à celle du Sud : 1,80 m au Nord pour 1,42 m au Sud. Sa longueur conservée est de 4,7 m, mais il s'interrompt brutalement au Sud. Au Nord, une dalle longue et étroite le clôt. Il ne présente pas de drain ni de hérisson. Il pourrait correspondre à un limites linearii, d'après la classification reprise par Raymond Chevallier : la largeur des limites varie entre 5 et 6 pieds romains ${ }^{11}$, ce qui correspond à la largeur du dallage. Il rappelle en outre que selon Digeste, le dallage n'est de rigueur qu'en ville ${ }^{12}$. Un dallage urbain accentue l'aspect spectaculaire de la rue et présente une fonction ostentatoire évidente ${ }^{13}$ : il montre la richesse de la ville et la puissance de ses habitants. Cette dimension démonstrative avait déjà été soulevée lors de la précédente campagne ${ }^{14}$. Le mur 01759, sur lequel a été mise au jour une délicate cuillère en os (Fig. 24a-b) vient fermer la pièce formée par les murs 01718,01628 et 01636 , édifiée au niveau 2 (Fig. 25).

Cette ligula à cuilleron piriforme présente un raccord au manche de section circulaire en forme de pointe. Ce type, qui n'est pas le plus répandu (on rencontre davantage de cochlearia en os), est attesté à Tarse ${ }^{15}$ et il est notamment comparable au n ${ }^{\circ} 796$ du musée de Lyon $^{16}$.

$\mathrm{Au}$ Sud du mur (01759) dans l'angle nord-est de cette pièce, a été dégagée une fosse (01764) contenant une jarre complètement renversée (01763). Elle comprenait également un peson entier en terre ainsi qu'un fragment de bec de lampe hellénistique. Cet espace a été très certainement réutilisé comme poubelle. Nous avons choisi d'arrêter la fouille dans cette zone à la même altitude qu'en 2013.

Au Nord, nous avons également fouillé un foyer rectangulaire en terre crue (01766) (Fig. 26) de plus importantes dimensions que les dispositifs de feux retrouvés jusqu'à présent pour le chantier IV : environ $140 \mathrm{~cm}$ de long sur $65 \mathrm{~cm}$ de large pour 38 $\mathrm{cm}$ de profondeur. D'après la classification reprise

10) Sur la question des remparts de cette zone ouest du site de Porsuk, voir les observations de Tibet et Laroche-Traunecker 2015 , ainsi que celles de Beyer et Laroche-Traunecker, à paraître. Sur les aspects chronologiques, Beyer 2015 : surtout 102-106.

11) Chevallier $1997: 32.1$ pied romain correspond à $29,63 \mathrm{~cm}$.

12) Chevallier $1997: 112$.

13) Coulon $2007: 80$.

14) Beyer, Chalier, Kirner, Laroche-Traunecker et Tibet $2014: 330$.

15) Les cuillerons des ligulae de Tarse sont toutefois plus longs. Goldman $1950:$ pl. 271, $\mathrm{n}^{\circ} 1-3$.

16) Béal 1983. 


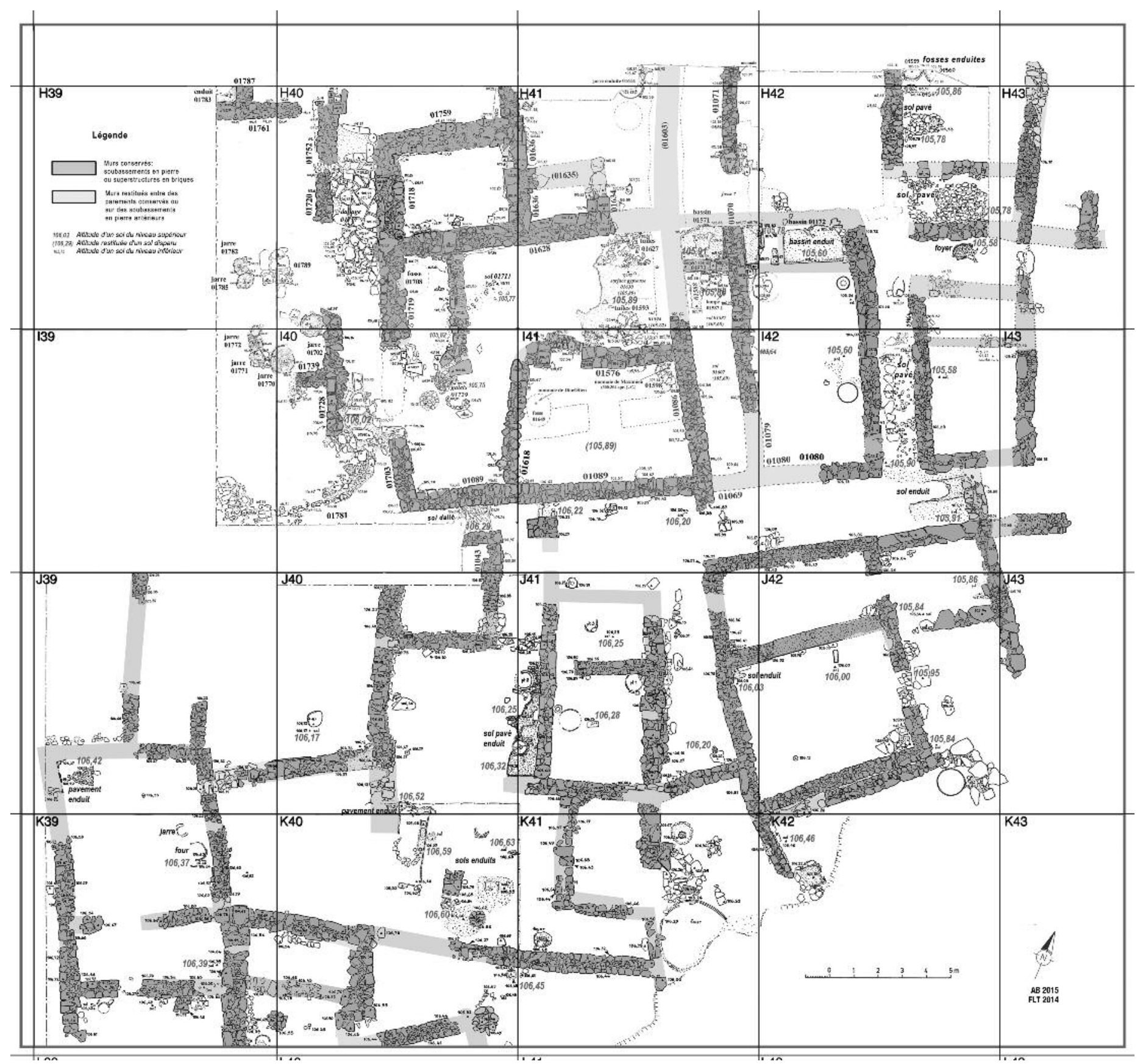

Fig. 22a : Chantier IV. Plan d'ensemble du niveau 1 (A.B./F.L.-T.). 


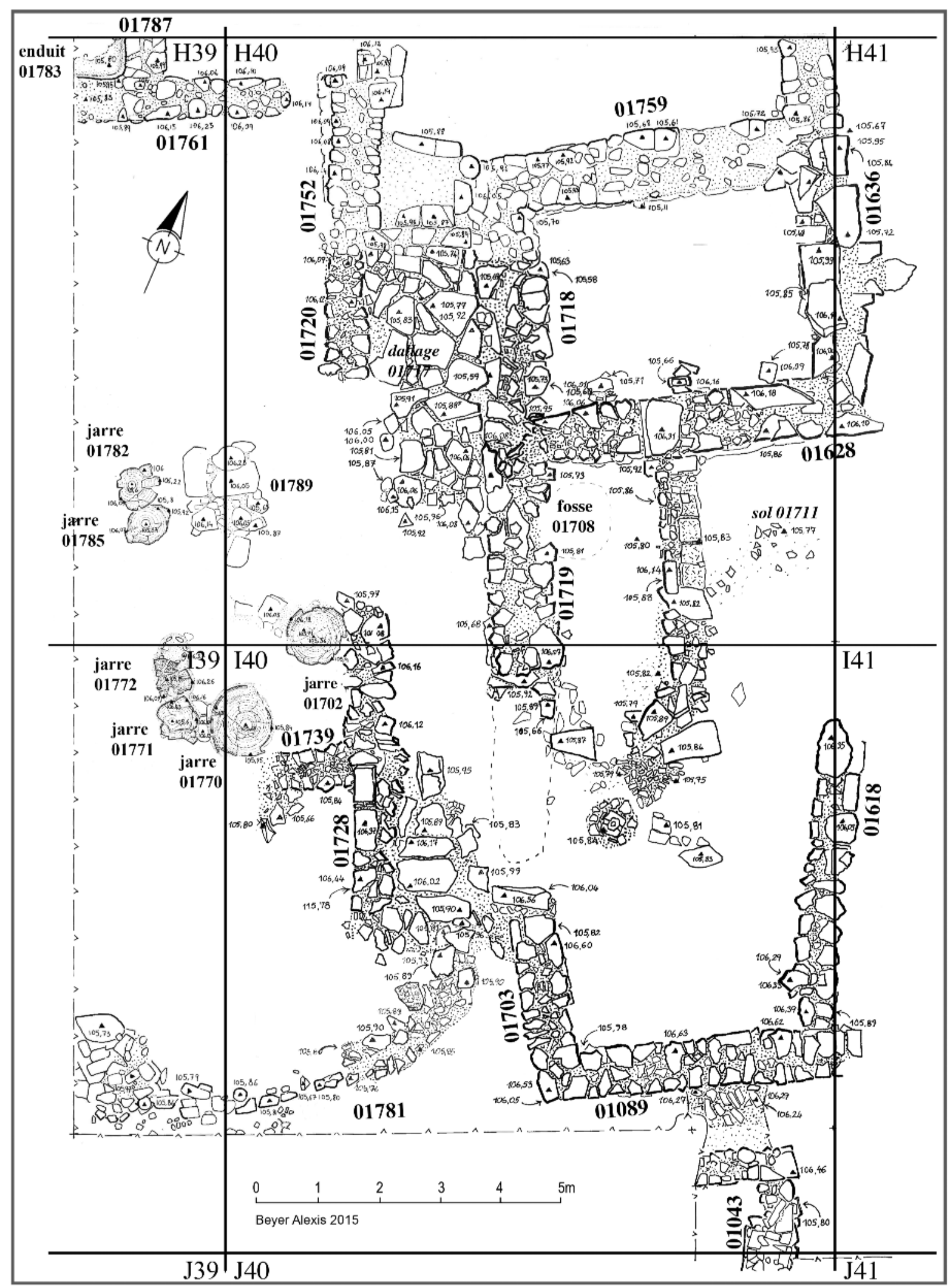

Fig. 22b : Chantier IV. Secteur fouillé, niveau 1 (A.B.). 


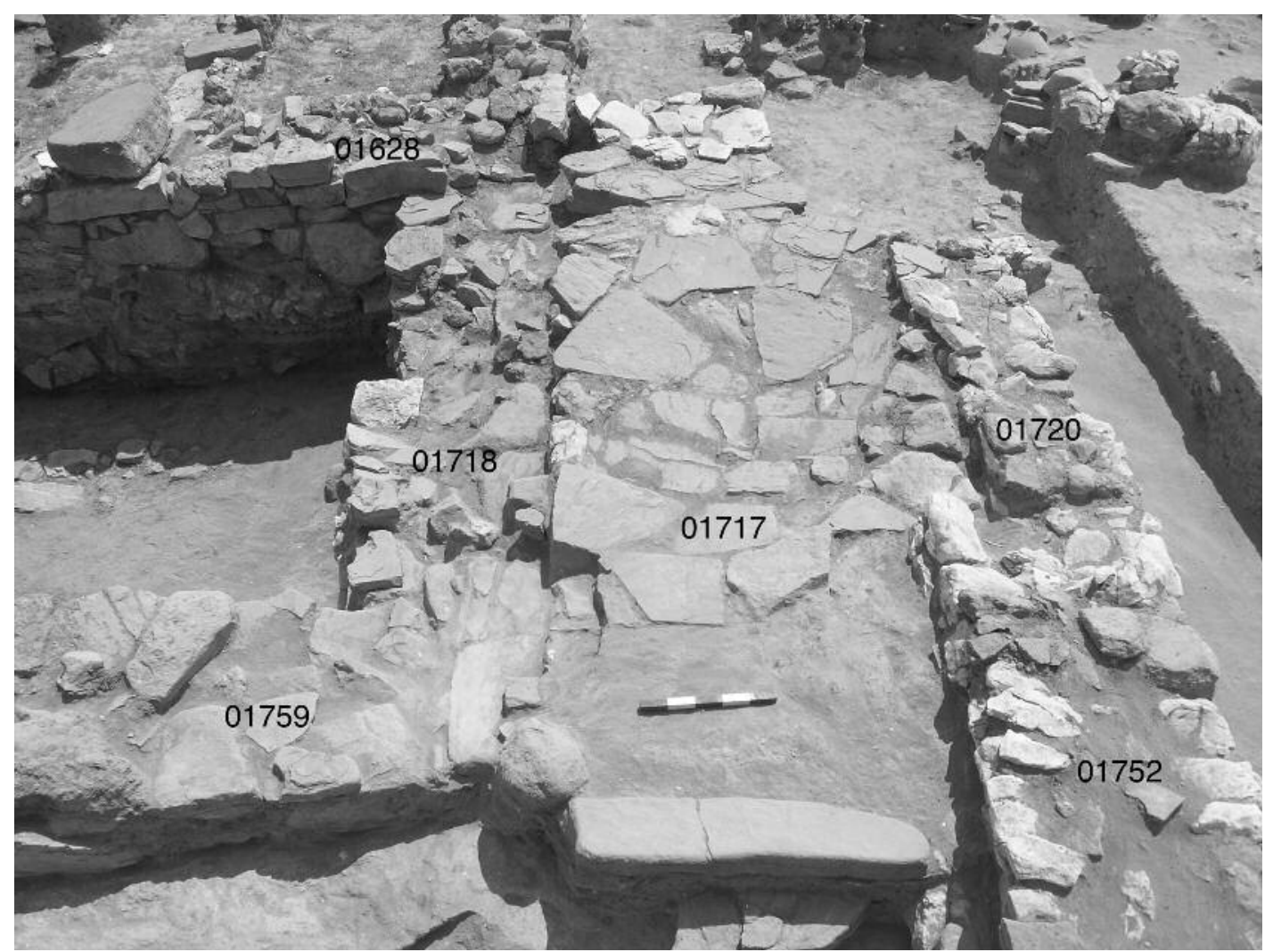

Fig. 23 : Chantier IV. Murs 01759 et 01728, dallage 01717. Vue vers le Sud.

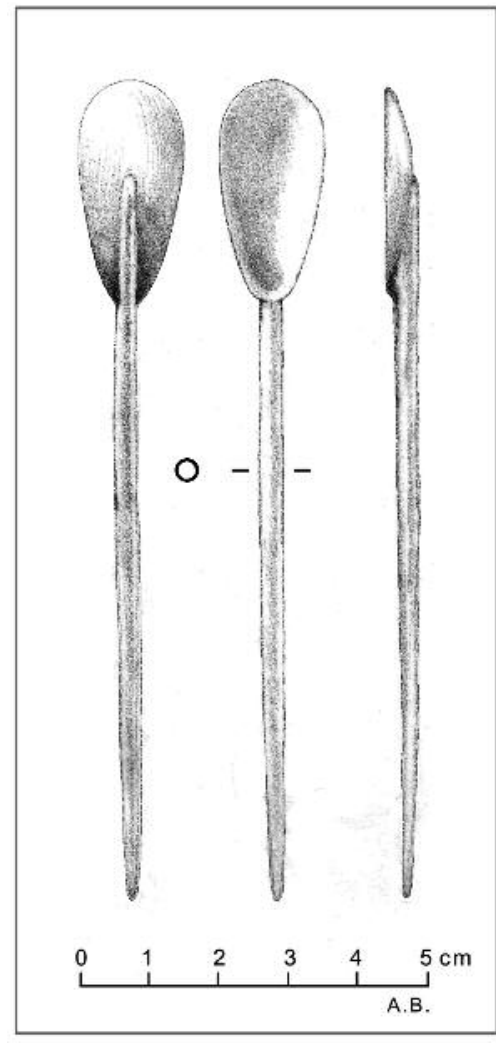

Fig. 24a : Chantier IV. Ligula en os 01758.0002 (dessin A.B.).

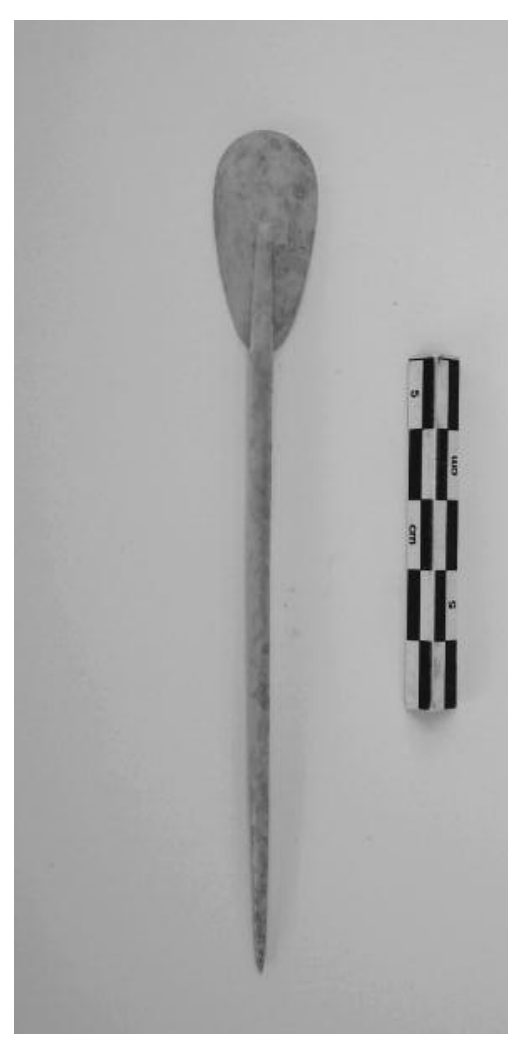

Fig. 24b : Ligula 01758.0002. 


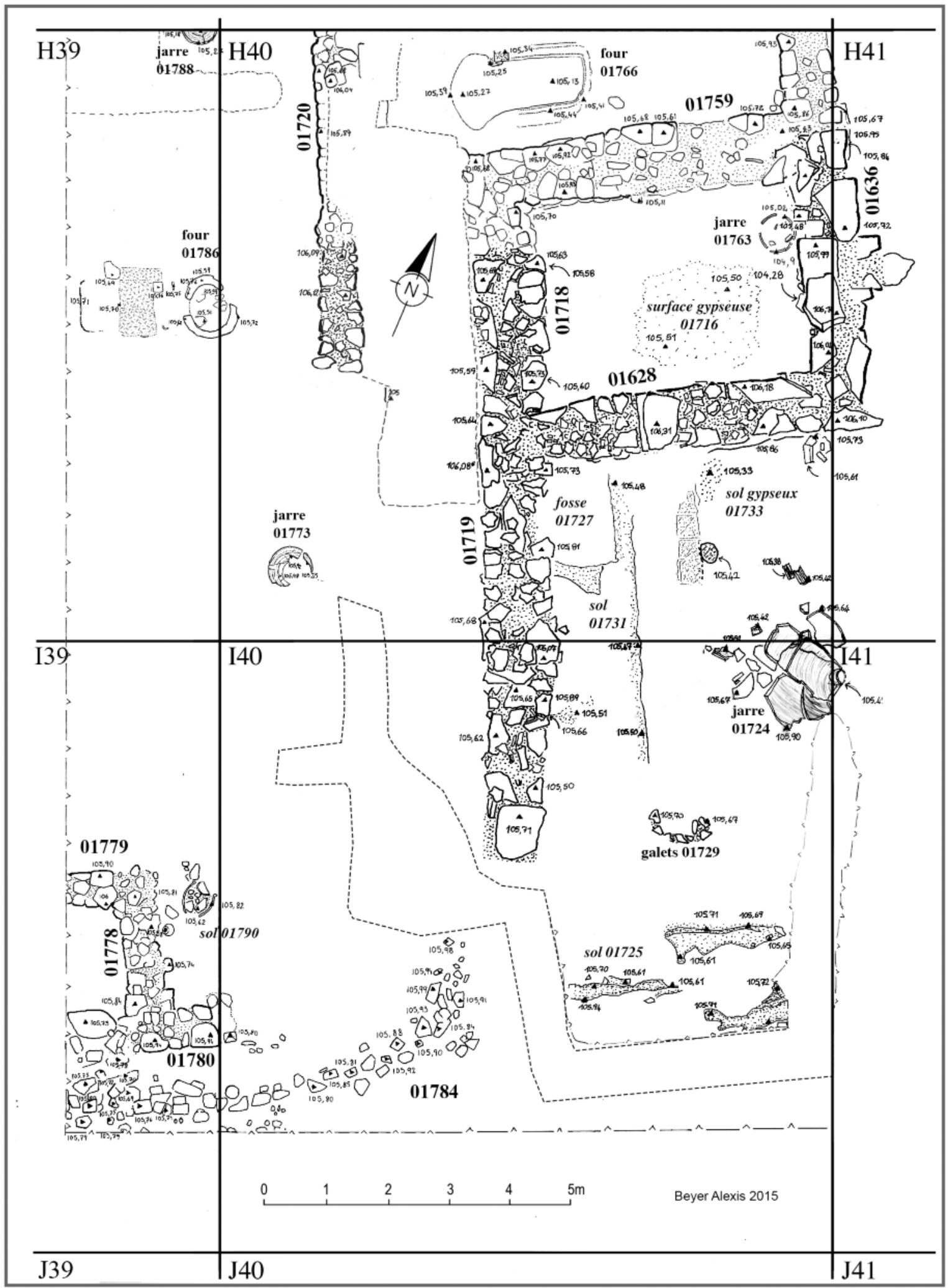

Fig. 25 : Chantier IV. Plan du niveau 2 (A.B.). 


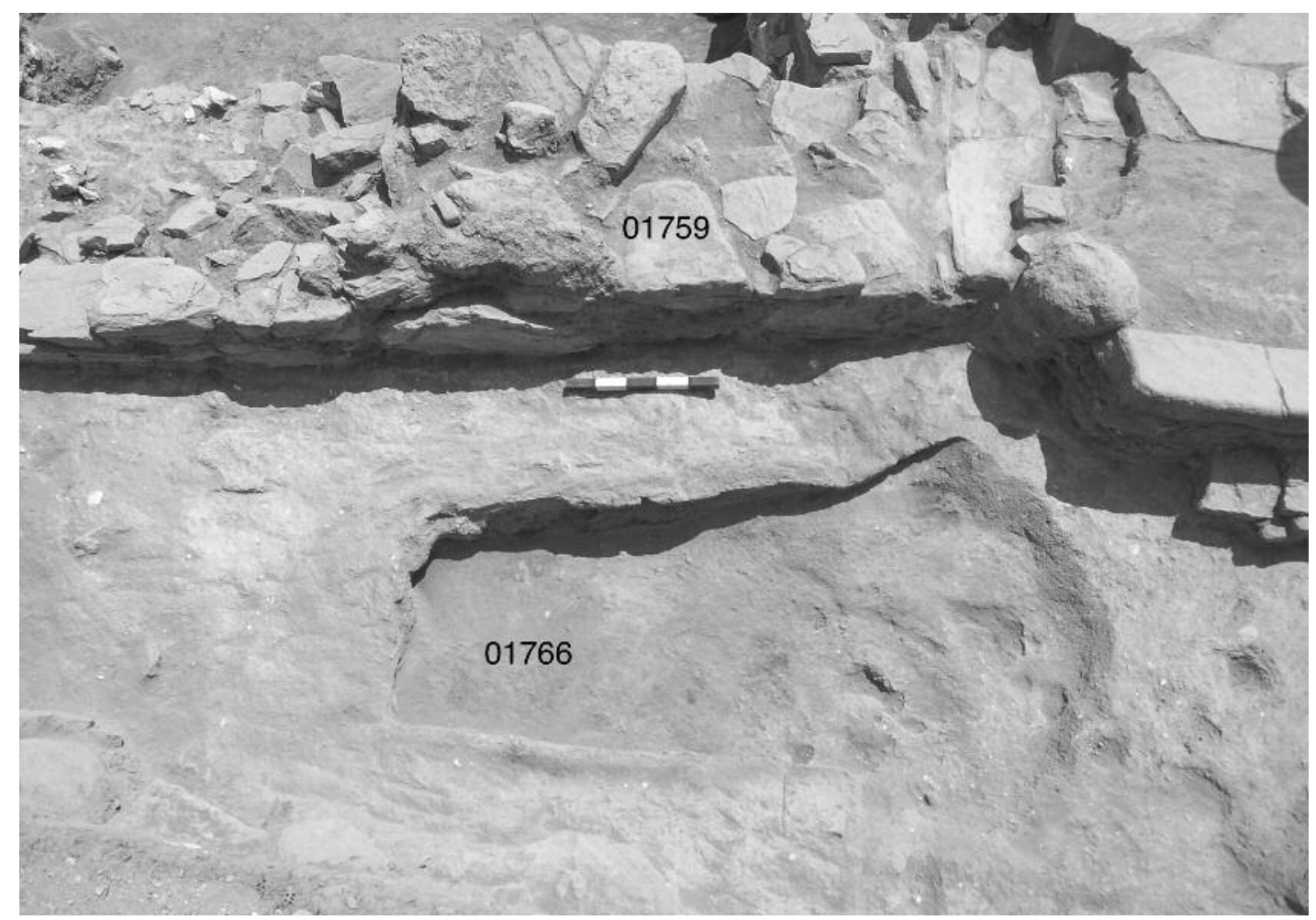

Fig. 26 : Chantier IV. Fosse de cuisson 01766. Vue vers le Sud.

par Anne-Sophie Martz ${ }^{17}$, ce dispositif serait plutôt à classer dans les fosses de cuisson, mal documentées car leurs traces archéologiques demeurent fragiles. La fosse de cuisson est attestée depuis la fin du IV millénaire av. J.-C. à Uruk et elle est encore utilisée aujourd'hui en Turquie et en $\operatorname{Iran}^{18}$. Elle est creusée et utilisée pour certaines occasions particulières, impliquant toujours la cuisson d'une grande quantité de nourriture. Dans les couches supérieures de cette fosse 01766 ont été retrouvés des os d'animaux (dont les restes d'un squelette de bovidé), du charbon de bois et des pierres. Elle a certainement servi à plusieurs reprises, comme en attestent les parois en terre crue et le gradient coloré dû à des températures élevées. La zone d'évacuation des cendres se situe à l'Ouest. A l'intérieur de la fosse, on a découvert des os d'animaux et de la céramique hellénistique.

D'ailleurs la céramique mise au jour dans l'ensemble de cette zone date de l'époque romaine pour le niveau 1 (tessons de sigillée orientale A) et hellénistique pour le niveau 2 (unguentarium, coupes à bandeaux peints...).

\section{Niveau 1 en H39 et I39}

Dans un deuxième temps nous avons ouvert une nouvelle zone de fouille à l'Ouest en I39 et H39 de 2,5 $\mathrm{m}$ sur 9,6 $\mathrm{m}$ dans laquelle nous avons dégagé une aire de stockage et de travail d'époque romaine composée de cinq jarres (Fig. 27). L'une d'entre elles (01702) avait été fouillée en $2013^{19}$. Ces jarres, proches de la surface, sont très abîmées, éclatées, corrodées et coupées pour deux d'entre elles au niveau de la panse. Nous n'avons pour aucune d'entre elles de profil complet. Pour établir la limite nord de l'aire de stockage des jarres, nous avons étendu en H39 vers le Nord la zone de fouille, sur une bande longue de 8,5 m et large de 2,5 m. Deux nouvelles jarres (01782 et 01785 ) sont apparues, elles aussi très abîmées. Dans cette zone, la céramique se compose notamment de sigillée orientale A. Nous y avons aussi découvert de nombreux fragments de verre ainsi qu'une figurine incomplète de taureau à bosse (Fig. 28). D'autres exemples, avec des variantes, ont été mis au jour au cours des campagnes antérieures ${ }^{20}$.

17) Martz $2011: 2$.

18) Martz $2011: 3$

19) Beyer, Chalier, Kirner, Laroche-Traunecker et Tibet $2014: 330$ et 331 fig. 5.

20) Chalier, Laroche-Traunecker, Lebreton, Tibet sous la dir. de Beyer $2009: 322$, fig. 8 ; Chalier, De Backer, Laroche-Traunecker, Lebreton, Tibet, sous la dir. de Beyer $2010: 226$, fig. 13. 


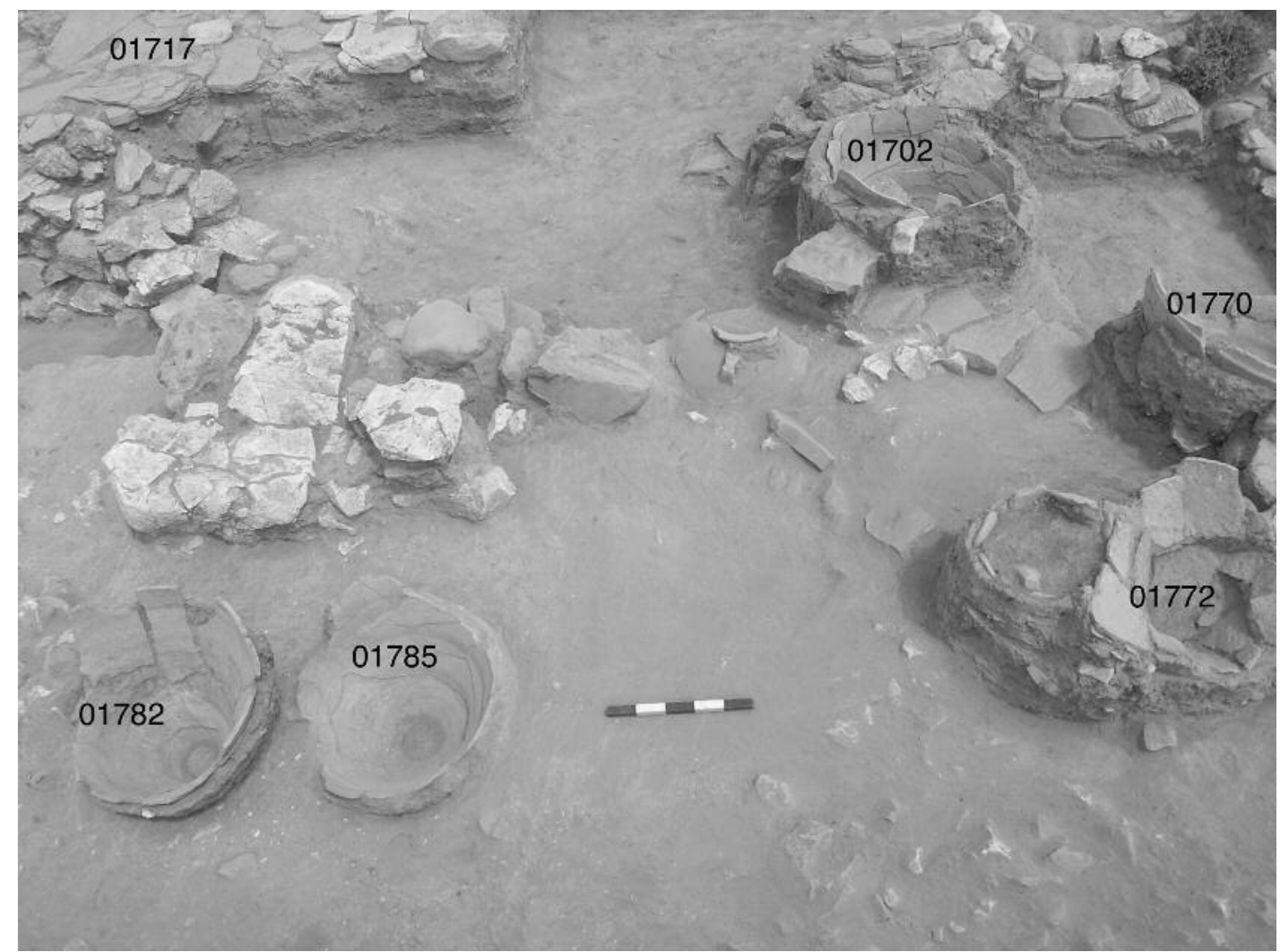

Fig. 27 : Chantier IV. Jarres 01782, 01785, 01172, 01770 et 01702 . Vue vers l'Est.

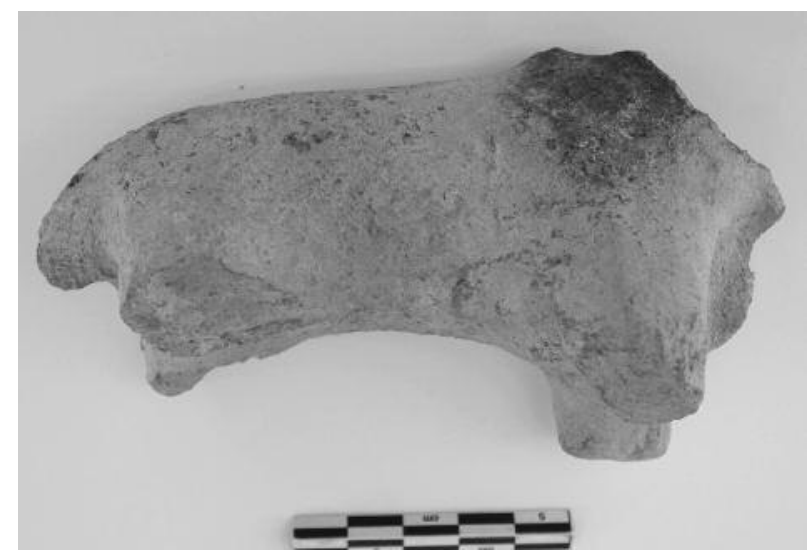

Fig. 28 : Chantier IV. Figurine de taureau à bosse en terre cuite 01774.0005 .

Plus rare, un manche de simpulum en bronze (Fig. 29a-b) a été dégagé. Le sommet de ce manche, plat et cannelé, est pourvu d'ergots latéraux et se termine en un crochet représentant une tête d'anatidé ou oiseau aquatique. Il manque la vasque. Le simpulum permettait de puiser et servir la boisson. Dans l'Antiquité, c'est un accessoire culturel utilisé dans le cadre du banquet, le plus souvent découvert dans un contexte funéraire ou domestique ce qui est le cas pour notre exemplaire. Des simpula incomplets ont été mis au jour à Tarse, dont un avec un manche plat et cannelé à ergots latéraux et une tête de canard $^{21}$. La vasque y est, là aussi, manquante et tous sont associés à un niveau d'habitation daté du $3^{\mathrm{e}}$ siècle av. J.-C et de la première moitié du $2^{\mathrm{e}}$ siècle av. J.-C. selon les archéologues. L'exemple de Porsuk, découvert dans un contexte plus récent que ceux de Tarse, peut également être rattaché au type 3 établi par Michel Feugère ${ }^{22}$ qui en cite quelques uns fort similaires découverts en Gaule méridionale et datés du $1^{\text {er }}$ siècle av. J.-C. Le type semble disparaître au $1^{\text {er }}$ siècle ap. J.-C.

Tout au Nord de l'aire fouillée, on a découvert un mur orienté Est-Ouest 01761 et son retour vers le Nord 01787 associés à un creusement enduit à l'angle et qui se poursuit dans la berme (Fig. 30). 


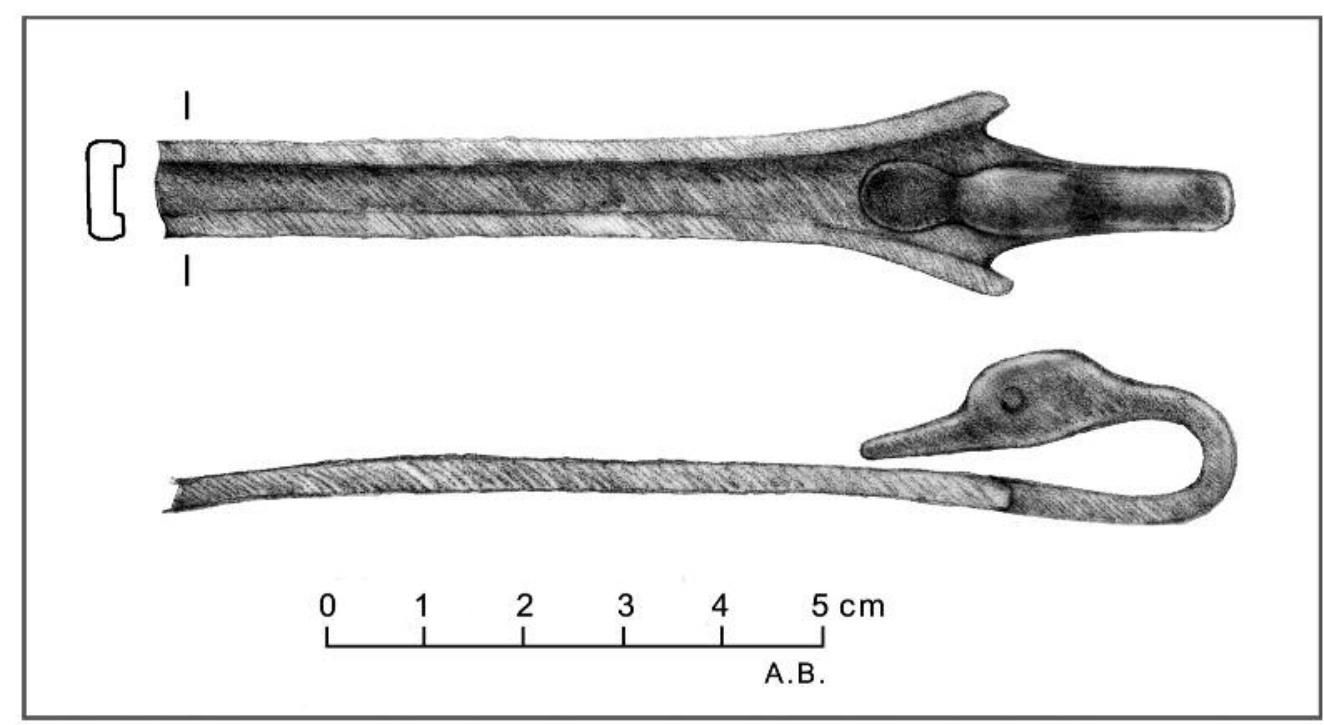

Fig. 29a : Chantier IV. Manche de simpulum en bronze 01774.0001 (dessin A.B.).

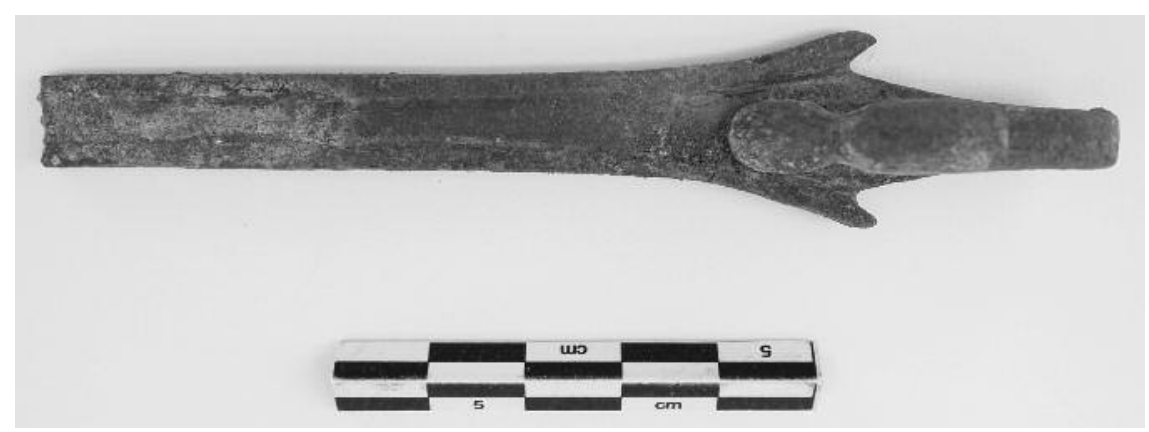

Fig. 29b : Simpulum 01774.0001.

Cet ensemble forme le niveau 1 , romain, de ce secteur et il conviendra lors de la prochaine campagne d'élargir l'espace de fouille vers l'Ouest en H39 et vers le nord en G39.

$\mathrm{Au}$ Sud de la zone nous avons repris le dégagement en suspens depuis 2013 de l'espace de circulation 01781. Il est composé de pierres plates de grès, de larges tessons de jarres et de morceaux de tuiles (imbrex et tegulae) remployés de façon à former une surface plane, bien qu'étroite. Ces tuiles sont identiques à celles découvertes lors des campagnes antérieures ${ }^{23}$. Ce modèle est assez mal documenté pour le moment, du moins en Anatolie et nous n'en connaissons à ce jour qu'un exemple qui semble proche : les tuiles réutilisées dans la nécropole de Tarse datée du $3^{\mathrm{e}}-4^{\mathrm{e}}$ siècle ap. J.-C. ${ }^{24}$. Toutefois, les photographies de la publication, en l'absence de dessin, ne nous permettent pas d'en être assuré. Sous cet espace de circulation nous avons mis au jour un état antérieur de niveau 2 d'époque hellénistique nommé 01784 et qui a dû fonctionner avec les murs 01778,01779 et 01780 .

\section{Niveau 2 en H39 et I39}

$\mathrm{Au}$ Sud de I39, après une importante couche d'abandon avec des éboulis de murs de niveau 1 , murs qui devaient fonctionner avec les jarres, nous avons atteint le niveau 2 (hellénistique) (Fig. 25) avec une surface d'occupation, un sol (01790) sur lequel se trouvaient une jarre renversée, une base de flacon en verre (Fig. 31), un fragment d'anse en verre et un vase ouvert complet, à engobe brun rouge appartenant à la céramique commune, de table 


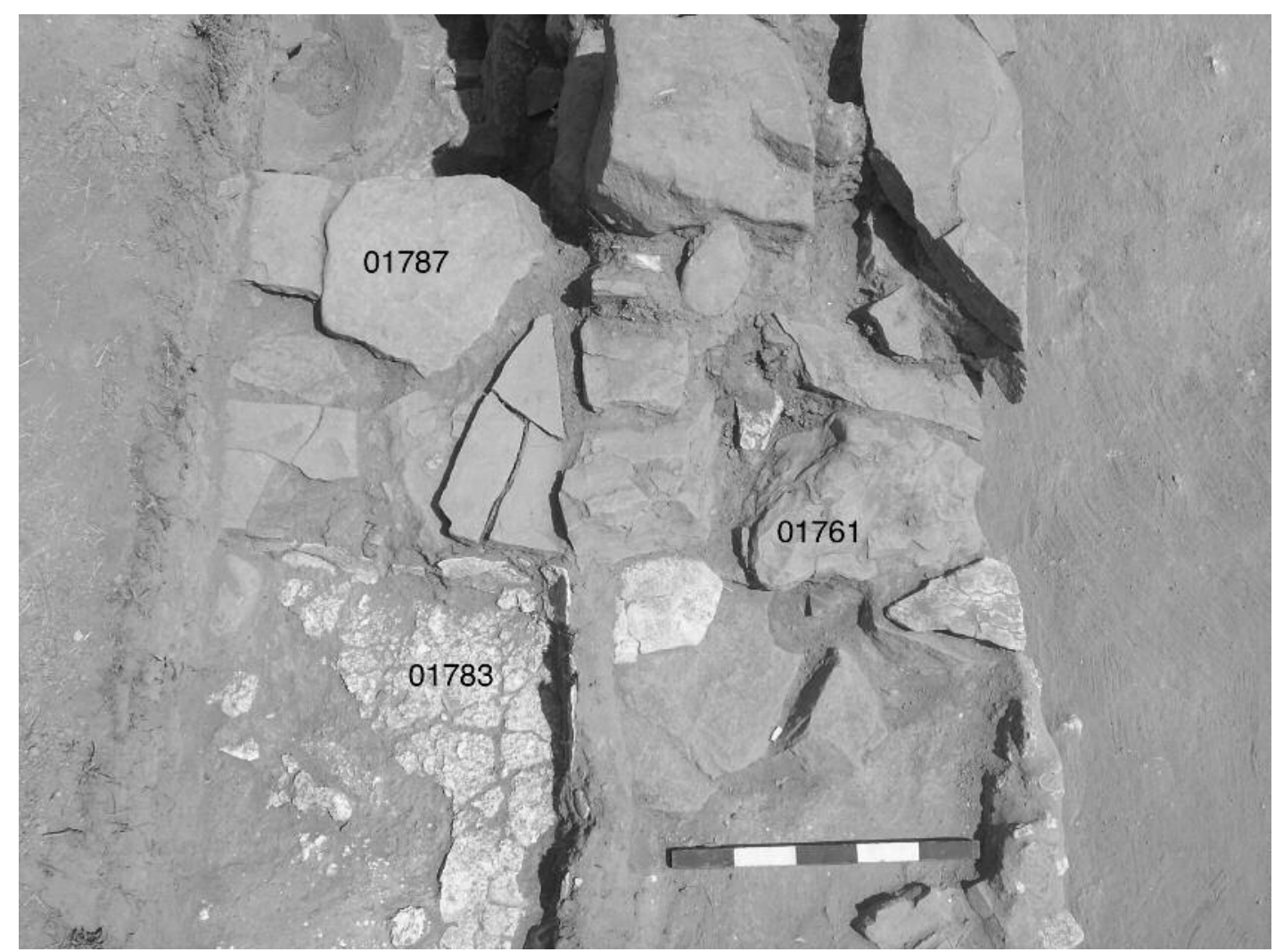

Fig. 30 : Chantier IV. Enduit 01783 et murs 01761 et 01787. Vue vers l'Est.

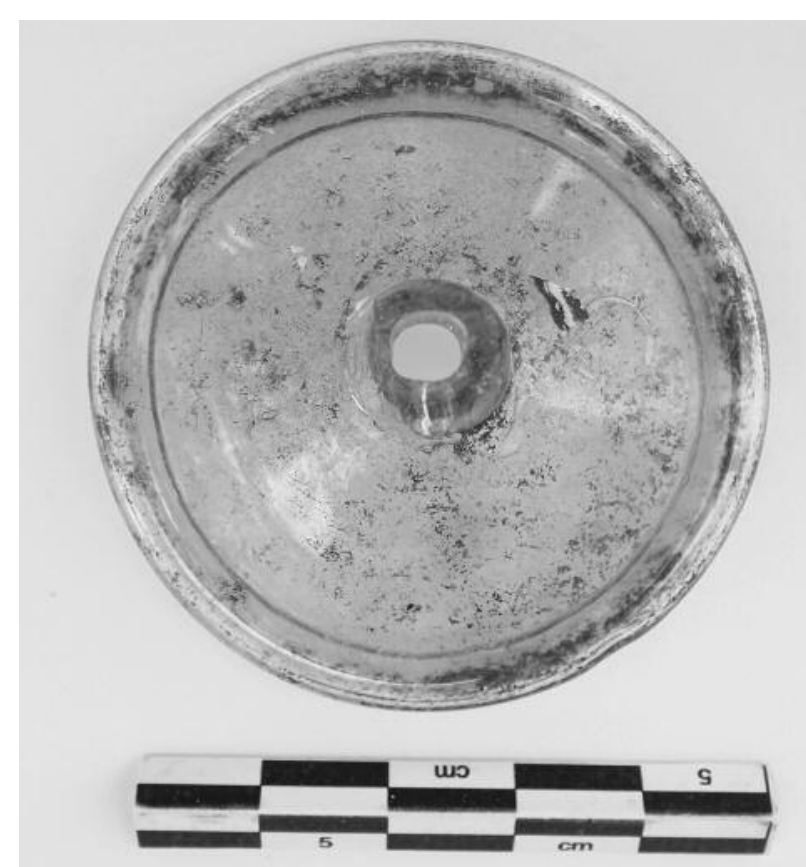

Fig. 31 : Chantier IV. Base de flacon en verre 01790.0001 . courante sur le site (Fig. 32a-b et 33). La jarre, très abîmée, reposait couchée sur le sol, renversée sur le côté, alors que le vase semblait être en place, révélant la fonction domestique de cet espace. Ce sol 01790 est associé à trois murs $(01778,01779$ et 01780$)$ composés de gypse et de grès et qui forment une pièce filant dans la berme ouest (Fig. 33). Nous n'avons pas retrouvé le sol de cette pièce.

Dans ce niveau, des fragments de verre ainsi que de la céramique hellénistique ont été découverts. Un lot de 23 clous et un autre de 12 ont également été trouvés. Ils rappellent ceux qui avaient été découverts en $2013^{25}$, et alors considérés comme des clous de chaussure. La tige de $0,95 \mathrm{~cm}$ de longueur en moyenne est de section quadrangulaire et la tête ronde présente une lèvre moyenne de $0,95 \mathrm{~cm}$ (Fig. 34). Il est difficile de dater les clous de chaussures, les aspects techniques de fabrication ou leur taille ne fournissant pas des éléments de datation. Néanmoins, M. Volken ${ }^{26}$ reprend les propos de Pline évoquant l'existence de sculponae pour le $2^{\mathrm{e}} \mathrm{s}$. ou le $3^{\mathrm{e}} \mathrm{s}$. av. J.-C. en Grèce, et rappelle qu'en Europe la chaussure en cuir est déjà attestée au milieu du $1^{\text {er }}$ s. av. J.-C. Les sculponae

25) Beyer, Chalier, Kirner, Laroche-Traunecker et Tibet 2014: 333 et 334 fig. 11.

26) Volken 2011: 316. 
PK15 IVN 01790.0002

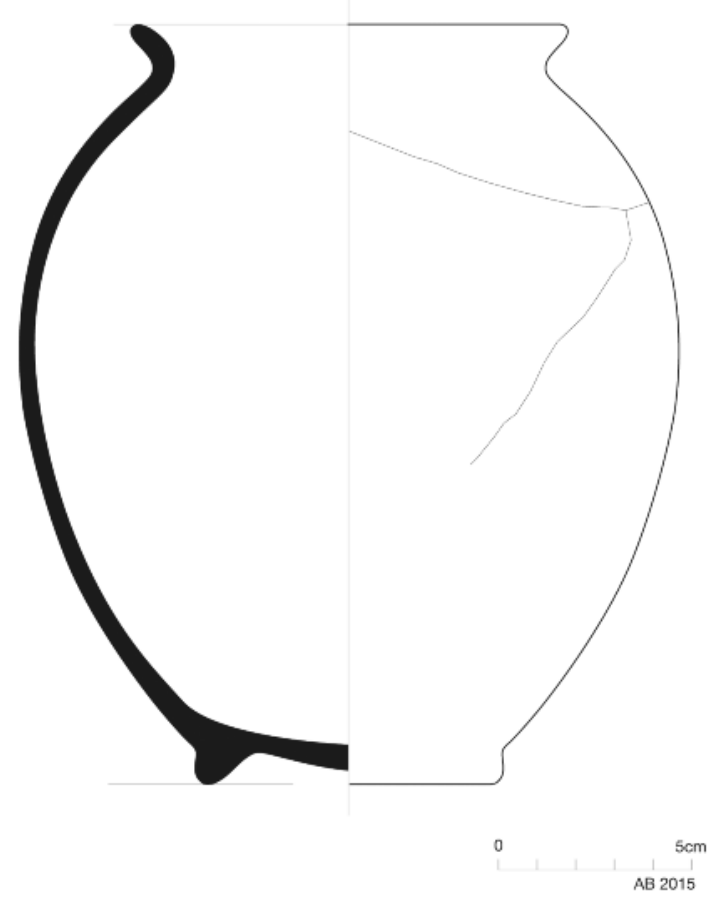

Fig. 32a : Chantier IV. Vase complet, céramique commune, période hellénistique 01790.0002 (dessin A.B.).

sont indifféremment militaires ou civiles. La semelle en cuir ou en bois est protégée par le clou qui lui donne du relief pour une meilleure adhérence et qui assure le maintien de la chaussure en réunissant la semelle et le dessus du soulier. Le clou traverse la semelle et il est ensuite recourbé. La hauteur de recourbement de la tige indique donc l'épaisseur exacte de la semelle. Il ne peut s'agir de clous perdus ou fragiles au vu du grand nombre de clous retrouvés dans le même contexte. En effet, dans un contexte fermé (comme un sol d'habitation), seuls les clous sont retrouvés, rarement la chaussure entière car le cuir se décompose. Les lots de clous découverts seraient donc "l'empreinte" négative de chaussures.

En H39 nous avons pu atteindre partiellement le niveau 2 avec un four circulaire en terre crue (01786) (Fig. 35) accompagné d'un aménagement de briques et de terre crue en partie enduit. Ce four présente deux ouvertures à l'Ouest et à l'Est permettant de charger en bois et de vider les cendres. Les parois sont en terre crue. Ce type de four alimentaire, en

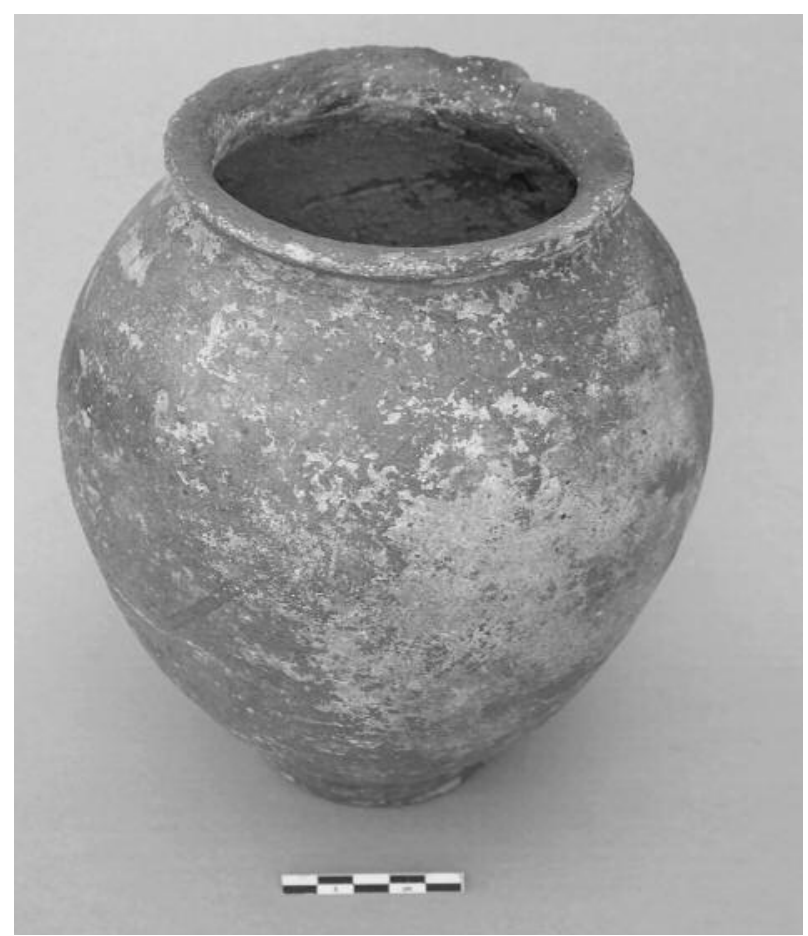

Fig. 32b : Vase 01790.0002.

dôme, est bien connu à Porsuk pour le niveau $2^{27}$. Une serpette (Fig. 36) en fer complète (seul manque le manche, qui était probablement en bois) a été trouvée à l'intérieur. Des morceaux de fer ainsi que ce qui ressemble à un creuset viennent témoigner d'activités métallurgiques.

Située au Sud du four 01786 et au même niveau, la jarre (01773) (Fig. 37) présente un profil complet et se distingue de par sa taille, plus petite, et de par sa forme des grandes jarres de stockage déjà mises au jour dans ce niveau. Elle a été cassée par l'installation de dalles plates et de la jarre (01702) appartenant au niveau 1. Une deuxième jarre (01788), coupée au niveau de la panse et basculant vers le Nord, a été découverte filant dans la berme nord de H39.

Partiellement fouillé puisque nous avons laissé en place des éléments du niveau 1, cet espace d'occupation est un espace domestique et artisanal. La céramique est de type hellénistique (Fig. 38).

Nous avons également consacré un temps certain à la mise en valeur des résultats de la campagne de 

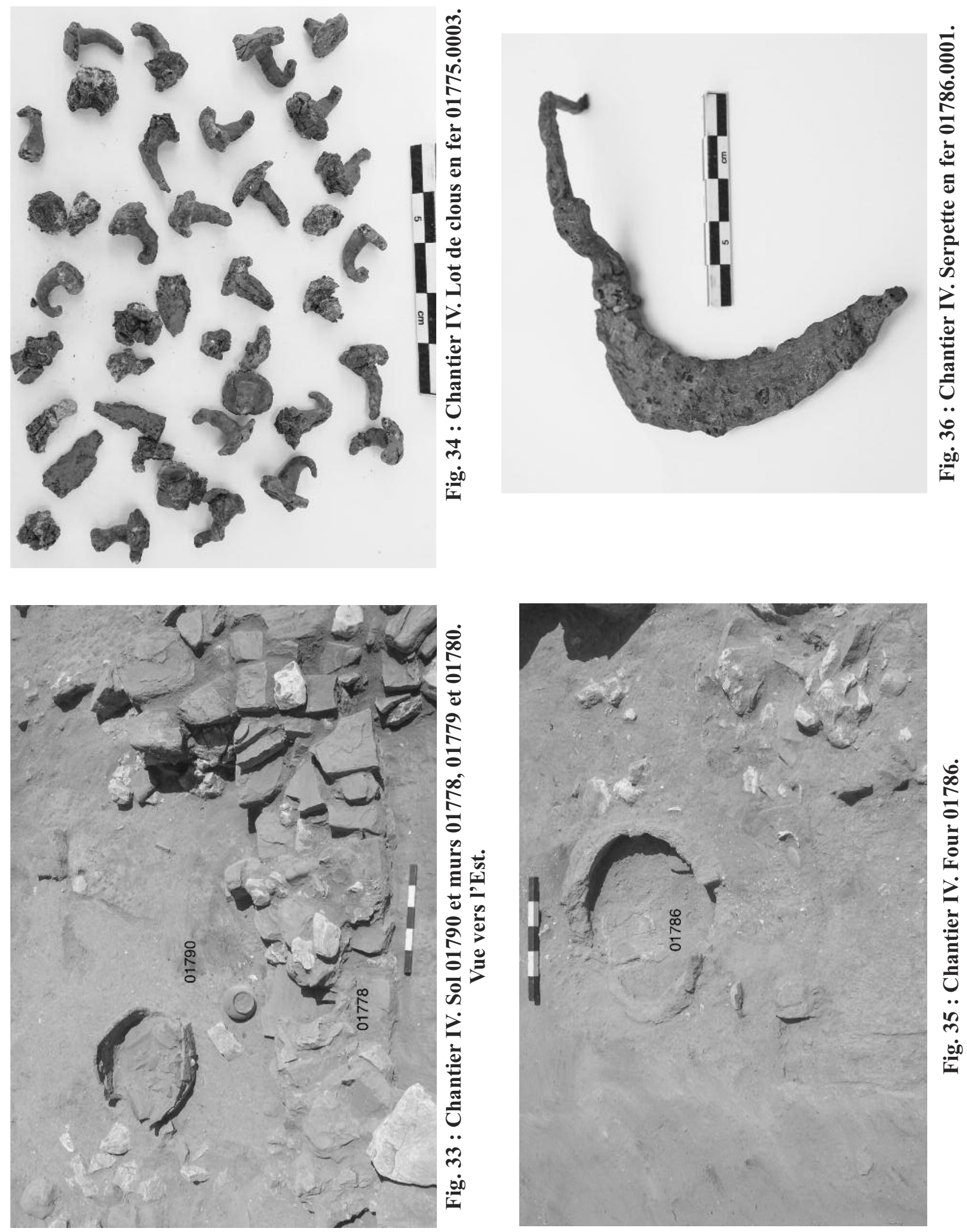

¿̊ 


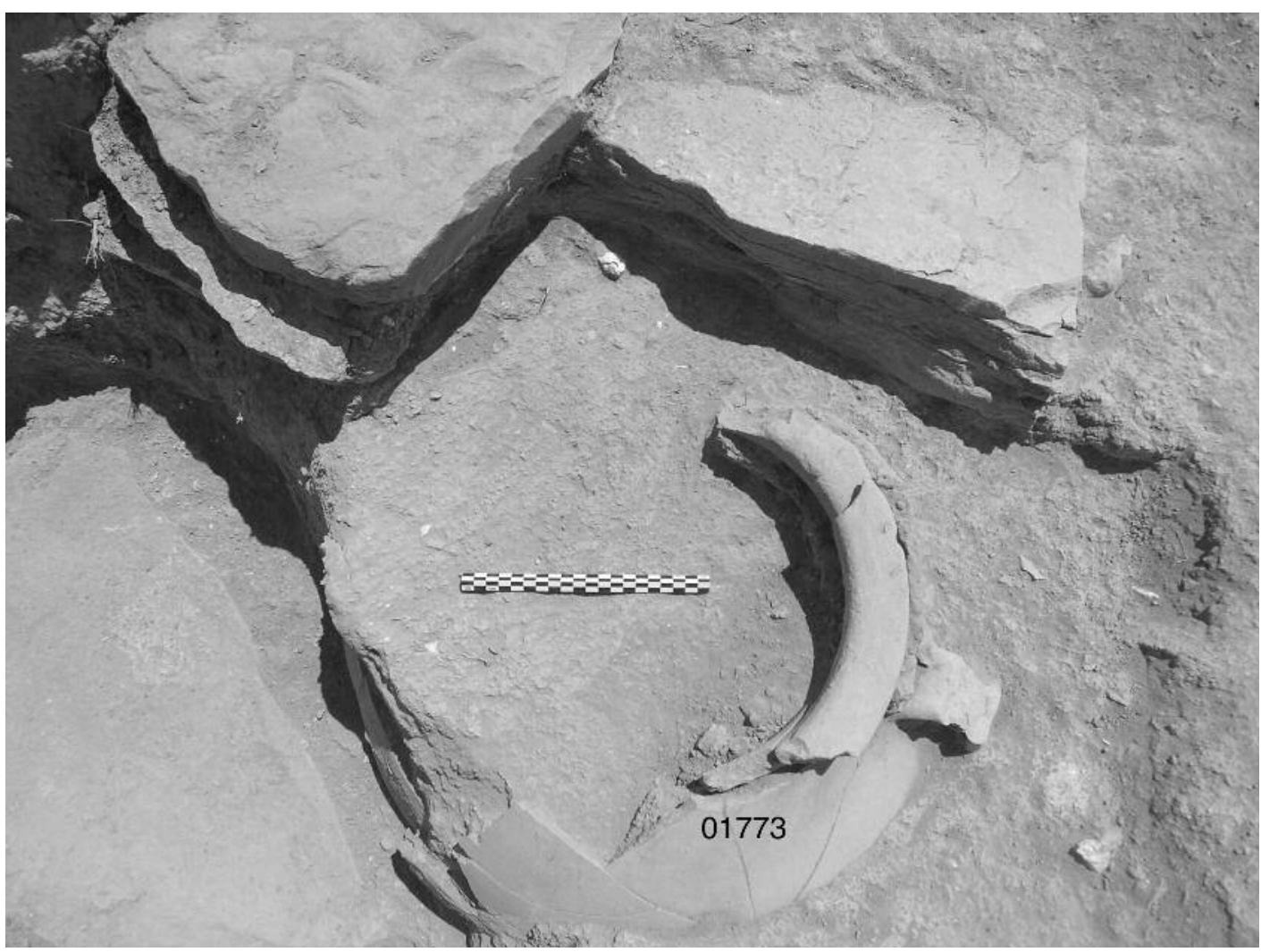

Fig. 37 : Chantier IV. Jarre 01773.

2015 à destination des visiteurs. Cette valorisation a consisté notamment à aménager le chemin qui mène au chantier IV et au panneau d'information qui le surplombe, permettant ainsi une compréhension des différents niveaux du chantier.

Il conviendra lors de la prochaine campagne d'étendre l'aire de fouille jusqu'à la limite occidentale des carrés H39 et I39 afin de compléter notre compréhension de cette zone.

\section{CONCLUSION}

On ne peut que souhaiter que les travaux de la mission de Porsuk puissent se poursuivre, dans le cadre d'une nouvelle direction, avec de nouvelles collaborations et un budget renforcé, digne du site et d'une des rares opérations françaises sur le plateau anatolien. Le relevé géophysique complet, tant attendu, devrait permettre de déceler les zones les plus susceptibles d'offrir des renseignements essentiels sur les divers niveaux représentés à Porsuk et d'alimenter par conséquent un nouveau programme scientifique. Dans l'immédiat, la poursuite des travaux, aussi bien au chantier II qu'au chantier IV, nous paraît bien nécessaire.

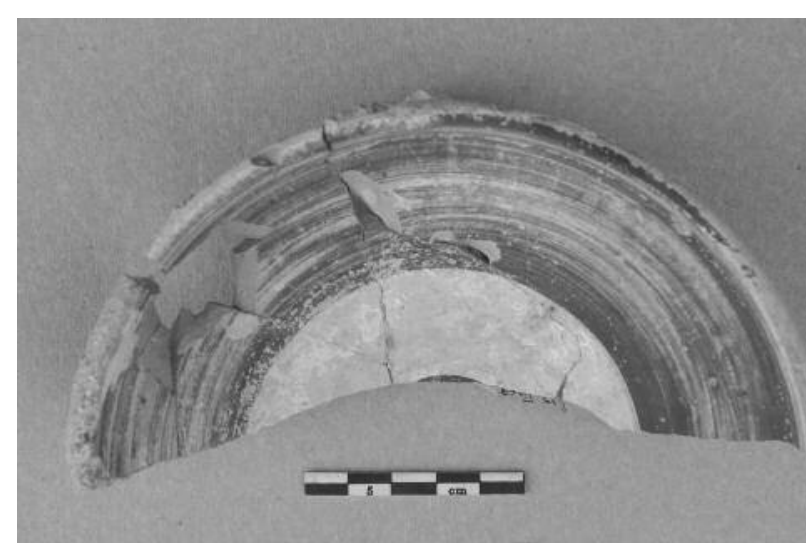

Fig. 38 : Chantier IV. Coupe à bandeaux peints hellénistique. 


\section{BIBLIOGRAPHIE}

Béal, J.-C., 1983 : Catalogue des objets de tabletterie du musée de la civilisation gallo-romaine de Lyon, Lyon.

Beyer, D., 2015 : "QQuelques nouvelles données sur la chronologie des phases anciennes de Porsuk, du Bronze Moyen à la réoccupation du Fer", in Beyer, D., Henry, O. et Tibet, A. (éds.), La Cappadoce méridionale de la préhistoire à la période byzantine, $3^{\text {èmes }}$ Rencontres d'archéologie de l'IFEA : 101-110.

Beyer, D., Chalier, I, Kirner, F., Laroche-Traunecker, F. et Tibet, A., 2014 : "Zeyve Höyük-Porsuk : rapport préliminaire sur la campagne 2013", Anatolia Antiqua XXII : 327-342.

Beyer, D., Karavul, C., Laroche-Traunecker, Fr. et Tibet, A., 2015 : " Rapport préliminaire sur les travaux de la mission archéologique de Zeyve höyük-Porsuk 2014", Anatolia Antiqua XXIII : 275-290.

Beyer, D. et Laroche-Traunecker, F., à paraître : " Le site de Zeyve Höyük-Porsuk aux époques hittite et néohittite. Remarques sur la succession des systèmes défensifs", in Mouton, A. (éd.), Actes du colloque L'hittitologie aujourd'hui, Istanbul, 2014, $5^{\text {èmes }}$ Rencontres d'archéologie de l'IFEA.

Castoldi, M. et Feugère, M., 1991 : "Les simpulums", in Feugère, M. et Rolley, C. (dir.), La vaisselle tardo-républicaine en bronze, Dijon : 61-88.

Chalier, I., Laroche-Traunecker, F., Lebreton, S., Tibet, A., sous la dir. de Beyer, D., 2009 : "Zeyve Höyük (Porsuk) : rapport sur la campagne de 2008”, Anatolia Antiqua XVII : 317-349.
Chalier, I., De Backer, F., Laroche-Traunecker, F., Lebreton, S., Tibet, A., sous la dir. de Beyer, D., 2010 : "Campagne 2009 de la mission archéologique de Zeyve Höyük (Porsuk)", Anatolia Antiqua XVIII : 215-242.

Chevallier, R., 1997 : Les voies romaines, Paris.

Coulon, G., 2007 : Les voies romaines en Gaule, Paris.

Goldman, H., 1950 : Excavations at Gözlü Kule, Tarsus, volume I, plates, The Hellenistic and Roman Periods, Princeton.

Kirner, F., 2015 : "Fonctions des espaces des niveaux hellénistiques et romains du site de Porsuk", in Beyer, D., Henry, O. et Tibet, A. (éds.), La Cappadoce méridionale de la préhistoire à la période byzantine, $3^{\mathrm{mes}}$ Rencontres d'archéologie de l'IFEA : 145-158.

Martz, A.S., 2011 : Les dispositifs de cuisson domestiques au Proche-Orient d'après les sources archéologiques $\left(I I I^{e}\right.$ s. av. JC - III ap. JC), http://hal.archivesouvertes.fr/hal-00608958

Tibet, A. et Laroche-Traunecker, F., 2015 : “"Les fortifications occidentales de Porsuk, restitution et modélisation des états les plus anciens", in Beyer, D., Henry, O. et Tibet, A. (éds.), La Cappadoce méridionale de la préhistoire à la période byzantine, $3^{\text {èmes }}$ Rencontres d'archéologie de l'IFEA : 111-130.

Volken, M., 2011 : "Les clous de chaussures du site de Pfyngut : les bases d'une typo-chronologie", in "Pfyn/Finges, Evolution d'un terroir de la plaine du Rhône", Cahiers d'archéologie romande 121 : 315-414. 


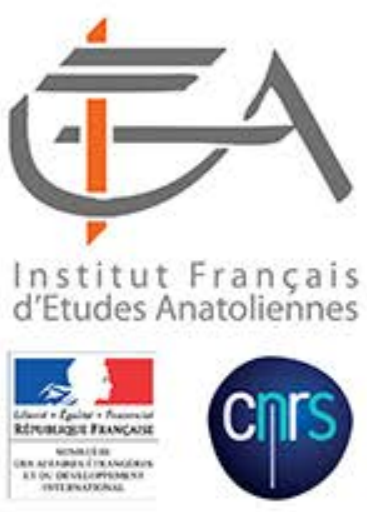

Eurômos : le temple de Zeus vu de l'Est (cliché Sönmez Alemdar).

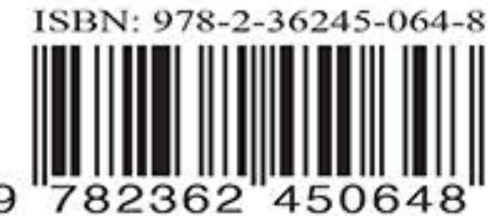

